OPEN ACCESS

Edited by:

Sha Wu,

Southern Medical University, China

Reviewed by:

Till Kaltofen,

Ludwig Maximilian University of

Munich, Germany

Elba Mónica Vermeulen,

Academia Nacional de Medicina,

Argentina

*Correspondence:

Yafei Huang

huangy2018@hust.edu.cn

Wanjiang Zeng

wjzeng@tjh.tjmu.edu.cn

${ }^{\dagger}$ These authors have contributed equally to this work

Specialty section:

This article was submitted to Immunological

Tolerance and Regulation,

a section of the journal

Frontiers in Immunology

Received: 14 June 2021

Accepted: 29 July 2021

Published: 17 August 2021

Citation:

Yu L, Zhang Y, Xiong J, Liu J, Zha Y, Kang Q, Zhi P,

Wang $Q$, Wang $H$, Zeng $W$ and

Huang Y (2021) Activated $\gamma \delta T$ Cells With Higher CD107a Expression and Inflammatory Potential During Early Pregnancy in Patients With Recurrent Spontaneous Abortion.

Front. Immunol. 12:724662. doi: 10.3389/fimmu.2021.724662

\section{Activated $\gamma \delta \mathrm{T}$ Cells With Higher CD107a Expression and Inflammatory Potential During Early Pregnancy in Patients With Recurrent Spontaneous Abortion}

\author{
Long Yu ${ }^{1,2 t}$, Yang Zhang ${ }^{3,4 t}$, Jinfeng Xiong ${ }^{3}$, Jianjun Liu $^{2}$, Ying Zha ${ }^{3}$, Qi Kang ${ }^{3}$, Pan Zhi ${ }^{3}$, \\ Qiang Wang ${ }^{1}$, Hui Wang ${ }^{3}$, Wanjiang Zeng ${ }^{3 *}$ and Yafei Huang ${ }^{2 *}$ \\ ${ }^{1}$ Department of Immunology, Medical College, Wuhan University of Science and Technology, Wuhan, China, ${ }^{2}$ Department of \\ Pathogen Biology, School of Basic Medicine, Tongji Medical College, Huazhong University of Science and Technology, Wuhan, \\ China, ${ }^{3}$ Department of Obstetrics and Gynecology, Tongji Hospital, Tongji Medical College, Huazhong University of Science and \\ Technology, Wuhan, China, ${ }^{4}$ Department of Obstetrics and Gynecology, The Second Hospital of Chaoyang City, Chaoyang, China
}

Previous studies have reported the involvement of $\gamma \delta$ T cells in recurrent spontaneous abortion (RSA); however, both pathogenic and protective effects were suggested. To interrogate the role of $\gamma \delta$ T cells in RSA, peripheral blood from RSA patients and healthy women with or without pregnancy were analyzed for $\gamma \delta$ T cells by flow cytometry $(n=9-11$ for each group). Moreover, the decidua from pregnant RSA patients and healthy controls (RSA-P and HC-P group, respectively) was simultaneously stained for $\gamma \delta \mathrm{T}$ cells by immunohistochemistry $(\mathrm{IHC})$ and bulk sequenced for gene expression. Our results demonstrated that the frequencies of peripheral $\gamma \delta T$ cells and their subpopulations in RSA patients were comparable to that in healthy subjects, but the PD1 expression on $\mathrm{V} \delta 2^{+}$cells was increased in pregnant patients. Furthermore, peripheral ${\mathrm{V} \delta 2^{+}}^{+}$cells in RSA-P patients demonstrated significantly increased expression of CD107a, as compared to that in pregnant healthy controls. In addition, RSA-P patients had higher proportion of IL-17A-secreting but not IL-4-secreting V $\delta 2^{+}$cells compared to the control groups. In decidua, an inflammatory microenvironment was also evident in RSA-P patients, in which CCL8 expression and the infiltration of certain immune cells were higher than that in the HC-P group, as revealed by transcriptional analysis. Finally, although the presence of $\gamma \delta T$ cells in decidua could be detected during pregnancy in both RSA patients and healthy subjects by multicolor $\mathrm{IHC}$ analysis, the expression of CD107a on $\gamma \delta$ T cells was markedly higher in the RSA-P group. Collectively, our results indicated that the increased activation, cytotoxicity, and inflammatory potential of peripheral and/or local $\gamma \delta$ T cells might be responsible for the pathogenesis of RSA. These findings could provide a better understanding of the role of $\gamma \delta$ T cells in RSA and shed light on novel treatment strategies by targeting $\gamma \delta$ T cells for RSA patients.

Keywords: $\gamma \delta$ T cells, recurrent spontaneous abortion (RSA), PD1, CD107a, IL-17A 


\section{INTRODUCTION}

With an incidence of $1 \%-3 \%$ worldwide $(1,2)$, RSA was defined as two or more consecutive pregnancy losses prior to the 20th week of gestation. Although many causes have been implicated in the occurrence of RSA, such as abnormal chromosome, endocrine dyscrasia, reproductive malformation, and infection, the etiology of RSA is still elusive; approximately $50 \%$ of RSA is diagnosed without specifically defined cause of abortion (3) and is therefore called unexplained RSA (URSA). Nonetheless, increasing evidence has suggested that URSA likely results from local (i.e., maternal-fetal interface) or systemic immune disorder.

Pregnancy is an immunological enigma wherein semiallogenic fetal antigens are present at the feto-maternal interface. Therefore, maternal immune system was originally hypothesized to be "inert" or "suppressive" during gestation to secure the success of pregnancy, as proposed by Sir Peter Medawar in 1953 (4). However, current data suggest that the successful pregnancy requires an active, robust, dynamic, and tightly regulated immune system across the three stages of pregnancy (5). In the first trimester, maternal immune system is better pro-inflammatory to allow the successful implantation and placentation, and it must be subsequently switched to be anti-inflammatory to support fetal growth during the second trimester. Finally, in the third trimester, a second inflammatory response is necessary for the initiation of parturition. In this scenario, multiple immune cells have to coordinate to create an optimal immune milieu both at the maternal-fetal interface and in periphery for the success of pregnancy. On the contrary, the dysregulation of peripheral or local immune system might lead to the occurrence of RSA. To date, changes of NK cells, macrophages, neutrophils, and $\alpha \beta \mathrm{T}$ cells during heathy pregnancy and RSA have been extensively investigated (6); however, the role of $\gamma \delta \mathrm{T}$ cells remains less characterized.

As one of the three lymphocyte populations that express clonally distributed antigen receptors, $\gamma \delta \mathrm{T}$ cells, unlike $\alpha \beta$ $\mathrm{T}$ cells and $\mathrm{B}$ cells of adaptive immune system, often possess a pre-activated phenotype in the steady state (7). In contrast to $\alpha \beta$ $\mathrm{T}$ cells that recognize peptide antigens presented by MHC molecules (pMHC complex), $\gamma \delta \mathrm{T}$ cells are instead capable of reacting to a variety of antigens ranging from free peptides, lipids, phosphoantigens, and intact proteins such as MHC-I-like molecules, to pMHC complex $(8,9)$. Upon antigen recognition and stimulation, $\gamma \delta \mathrm{T}$ cells can be further activated and exert multiple functionalities, including cytotoxicity, interaction with other immune cells, and antigen presentation to $\alpha \beta \mathrm{T}$ cells (10, 11). Therefore, $\gamma \delta \mathrm{T}$ cells are considered to be the bridge between innate and adaptive immunity and have an important role in health and diseases. The role of $\gamma \delta \mathrm{T}$ cells in pregnancy has been suggested since 1992, when Born and colleagues found that reproductive tract $\gamma \delta \mathrm{T}$ cells are increased nearly 100 -fold in pregnant animals compared with nonpregnant animals (12). Simultaneously, Mincheva-Nilsson et al. identified a high number of $\gamma \delta \mathrm{T}$ cells in the human decidua during early pregnancy (13), which was confirmed by subsequent studies $(14,15)$, implying the important role of $\gamma \delta$ T cells in pregnancy.
To date, both pathogenic and protective effects of $\gamma \delta \mathrm{T}$ cells on pregnancy have been reported. Psarra et al. found that a significantly higher number of RSA patients harbored an increased population of $\gamma \delta \mathrm{T}$ cells in peripheral blood (16), Talukdar et al. found that IFN $\gamma$ - and IL-17-producing $\gamma \delta$ $\mathrm{T}$ cells were increased in RSA patients (17), and both groups suggested that these $\gamma \delta$ T cells are pathogenic. On the other hand, human decidual $\gamma \delta \mathrm{T}$ cells showed a dominantly TGF- $\beta$ - and IL-10-expressing profile during early pregnancy (18), and later investigation reported that these decidual $\gamma \delta \mathrm{T}$ cells could upregulate the biological functions of trophoblasts via IL-10 secretion in early human pregnancy (19) and thus ensure the success of pregnancy.

Human $\gamma \delta$ T cells are a heterogeneous population that can be divided into subpopulations according to their TCR usage (e.g., $\mathrm{V} \delta 1, \mathrm{~V} \delta 2$, and $\mathrm{V} \delta 3$ ). $\mathrm{V} \delta 2^{+}$cells are the predominant $\gamma \delta$ $\mathrm{T}$-cell subsets in the peripheral blood, and these cells are often regarded as an innate-like cells by carrying a semi-invariant $\mathrm{V} \gamma 9$ (JP)V $\delta 2$ TCR. Most V $\delta 2^{-} \gamma \delta$ T cells are $\mathrm{V} \delta 1^{+}$cells that distribute in tissues and exhibit adaptive-like features (7). Each subpopulation is further subject to the regulation of local microenvironment and antigen stimuli and then differentiates into diverse functional populations, which is similar to Th1, Th2, Th17, and Treg cells, or expresses a different array of molecules related to cytotoxicity (e.g., perforin, granzyme B, Fas ligand, and CD107a) (20) and activation/exhaustion (e.g., CD25, PD1 and TIM-3) (21). Therefore, the distinct results described above could be due to the functional heterogeneity of $\gamma \delta \mathrm{T}$-cell subsets. To reconcile this discrepancy, this study was designed to characterize the subpopulations and functional profiles of peripheral $\gamma \delta$ T cells from RSA patients and healthy women with or without pregnancy by flow cytometry. In addition, the decidua from pregnant women with or without RSA was stained for $\gamma \delta \mathrm{T}$ cells by immunohistochemistry (IHC) and bulk sequenced for gene expression to compare the functional properties of local $\gamma \delta$ $\mathrm{T}$ cells.

\section{METHOD}

\section{Study Participants}

Twenty-one RSA patients, namely, 10 pregnant (RSA-P) women and 11 un-pregnant (RSA-UP) women, were included for this study. RSA patients were defined as women with a history of two or more consecutively miscarriage without genetic, endocrine, uterine, or autoimmune abnormalities as well as other infections. Twenty-one age-matched healthy women with no history of miscarriage and without other complications or infections, namely, 11 healthy pregnant (H-P) and 10 healthy un-pregnant (H-UP) women, were recruited as controls for comparison. Of note, subjects who had a positive test result for hepatitis B surface antigen (HBsAg), anti-cardiolipin antibody (ACL), Beta-2 glycoprotein 1 antibodies ( $\beta 2 \mathrm{GP} 1 \mathrm{Ab})$, lupus anticoagulant (LAC), or thyroglobulin (Tg) were also excluded from this study to make the comparison results interpretable. Clinical characteristics of the participants are presented in

Table 1. This study was approved by the institute ethics 
TABLE 1 | Clinical characteristics of the participants in this study.

RSA pregnant RSA-P $(n=10)$ Healthy pregnant H-P $(n=11) \quad$ RSA un-pregnant RSA-UP $(n=11)$ Healthy un-pregnant H-UP $(n=10)$

\begin{tabular}{|c|c|c|c|c|}
\hline Age (years) & $31.2 \pm 4.8$ & $31.1 \pm 3.9$ & $30.8 \pm 3.1$ & $26.5 \pm 3.8$ \\
\hline Gravidity & $3.5 \pm 1.6$ & $2.7 \pm 1.0$ & $2.5 \pm 0.7$ & $0.2 \pm 0.6$ \\
\hline Parity & $0.1 \pm 0.3$ & $1.3 \pm 0.5$ & NA & $0.2 \pm 0.6$ \\
\hline Sp. Abortions & $2.9 \pm 0.7$ & NA & $2.3 \pm 0.5$ & NA \\
\hline $\begin{array}{l}\text { Gestational } \\
\text { weeks }\end{array}$ & $8.4 \pm 1.8$ & $7.5 \pm 0.9$ & NA & NA \\
\hline
\end{tabular}

Data were expressed as mean $\pm S D$.

committee of Tongji Hospital (Ref. No. TJ-C20180201), and the informed consents were obtained from all participants.

\section{PBMC Isolation}

Peripheral blood samples from the four groups were collected in heparin anti-coagulated vacutainer tubes (BD Pharmingen, CA, USA). After diluted twice by PBS, the blood was added carefully onto the Ficoll layer (Blood: PBS: Ficoll = 1:1:1) and centrifuged at $800 \times g$ for $30 \mathrm{~min}$ with brake off. Mononuclear layer was obtained and washed twice by PBS. The PBMC aliquots were used immediately for Flow Cytometry Staining or stocked frozen in fetal calf serum containing 10\% DMSO and 5\% Dextran at $-80^{\circ} \mathrm{C}$ until further test.

\section{Cell Labeling and Flow Cytometric Analysis}

For surface staining, freshly collected blood was aliquoted $(100 \mu \mathrm{l})$ and stained by fluorochrome-conjugated monoclonal antibodies against $\mathrm{CD} 3, \gamma \delta \mathrm{TCR}, \mathrm{V} \delta 1, \mathrm{~V} \delta 2$, and PD1. After incubating with the $\mathrm{mAbs}$ for $30 \mathrm{~min}$ at $4^{\circ} \mathrm{C}$ in the dark, the blood sample was lysed by $2 \mathrm{ml}$ of lysis buffer (BD Pharmingen) for $8 \mathrm{~min}$, washed twice by $2 \mathrm{ml}$ of ice-cold FACS buffer (PBS containing $2 \%$ FCS and $0.1 \%$ azide), and then fixed in $300 \mu \mathrm{l}$ of $1 \%$ paraformaldehyde for flow cytometric analysis.

For intracellular staining of cytotoxicity-related molecules, $3 \times$ $10^{5}$ fresh isolated PBMCs were stained by fluorochromeconjugated monoclonal antibodies against $\mathrm{V} \delta 1, \mathrm{~V} \delta 2$, and $\mathrm{CD} 107 \mathrm{a}$ for $30 \mathrm{~min}$ at $4^{\circ} \mathrm{C}$ in the dark and then stained for intracellular perforin and granzyme $\mathrm{B}$ after fixation and permeabilization by the Cytofix/Cytoperm Kit (BD Pharmingen). The cells were washed twice before resuspended in $300 \mu \mathrm{l}$ of $1 \%$ paraformaldehyde for flow cytometric analysis.

While for intracellular cytokine staining, $1 \times 10^{6}$ fresh PBMCs were stimulated by a cocktail containing phorbol myristate acetate (PMA), ionomycin, and brefeldin a (BD Pharmingen) for $5 \mathrm{~h}$ in 24-well flat-bottom plates, thereafter, the cells were harvested and washed once by PBS for immunolabeling. The cells were stained by the abovementioned fluorochromeconjugated monoclonal antibodies against $\mathrm{V} \delta 1$ and $\mathrm{V} \delta 2$ for $30 \mathrm{~min}$ at $4^{\circ} \mathrm{C}$ in the dark and then divided into two parts and stained for IFN $\gamma$ and IL-4, or TNF $\alpha$ and IL-17A, respectively, after fixation and permeabilization. Finally, the cells were washed twice and resuspended in $300 \mu \mathrm{l}$ of $1 \%$ paraformaldehyde for flow cytometric analysis.

All the fluorochrome-conjugated monoclonal antibodies were listed in Supplementary Table S1. The flow cytometric analysis was performed on an BD LSR Fortessa instrument (BD Bioscience) and data were analyzed by FlowJo V10 (BD Bioscience).

\section{Tissue Preparation}

Decidua tissues were all collected from pregnant participants (the RSA-P and H-P subjects). After washing twice by PBS, the tissues were cryopreserved immediately for further RNA sequencing and $\mathrm{qRT}-\mathrm{PCR}$, or fixed with $4 \%$ paraformaldehyde for $48 \mathrm{~h}$, and then embedded in paraffin wax and sectioned at 3 $\mu \mathrm{m}$. The paraffin sections were proceeded and stained with hematoxylin/eosin for histological investigation; selected slides were used for IHC (2.7) and multicolor IHC (mIHC, 2.8).

\section{RNA Sequencing and Data Analysis}

The sample information for bulk sequencing is listed in Table 2. Total RNAs of decidua tissues were extracted using Trizol (Invitrogen, CA, USA) according to the manufacturer's instruction. Oligo(dT)-attached magnetic beads were used to purify mRNA, which then was fragmented into small pieces with fragment buffer at the appropriate temperature to generate the final library. The final library was amplified with phi29 to make DNA nanoball (DNB), which has more than 300 copies of one molecule; DNBs were loaded into the patterned nanoarray, and single-end 50-base reads were generated on the BGIseq500 platform (BGI-Shenzhen, China).

For differentially expressed gene (DEG) analysis, RNA-seq data were mapped to human genome (GRCh38) using HISAT2 (v2.2.0). FeatureCounts integrated into Subread (v2.0.0) was used for counting reads with GENECODE gene annotation (v34). Then, the analysis of DEGs was performed using DESeq2 R package (v1.30.0). DEGs were selected as follows: adjusted $p$-value $<0.05$ and $\mid \log 2$ FoldChange $\mid>1$. Gene counts were normalized by DESeq 2 and converted to $\log _{2}$ (normalized counts +1) format. With DESeq2, the Wald test is the default used for hypothesis testing of DEG analysis. The Benjamini and Hochberg method was used to adjust $p$-value. $\log _{2}$ FoldChange was calculated as follows: $\log _{2}$ (normalized counts group $1 /$ normalized counts group 2). $Z$-score of normalized gene expression by genes (each gene with six samples has a zero mean and standard deviation is 1) was shown by hierarchical clustering heatmap.

For GO and KEGG enrichment analysis, all DEGs found above were used for enrichment analysis. ClusterProfiler $\mathrm{R}$ package (v3.18.0) was used to perform GO (including Biological Process, Cellular Component and Molecular Function) and KEGG enrichment analysis. p-value was 
TABLE 2 | Clinical characteristics of the participants recruited for RNA-seq.

\begin{tabular}{|c|c|c|c|c|c|c|c|}
\hline Group & Sample & Age (years) & Gravidity & Parity & Spontaneous Abortion & Artificial Abortions & Sample GA/(D) \\
\hline \multirow[t]{3}{*}{ RSA-P } & RSA01 & 30 & 4 & 0 & 4 & 0 & 62 \\
\hline & RSA02 & 31 & 2 & 0 & 2 & 0 & 57 \\
\hline & RSA03 & 34 & 3 & 0 & 3 & 0 & 56 \\
\hline \multirow[t]{3}{*}{ HC-P } & HC01 & 33 & 3 & 2 & 0 & 1 & 55 \\
\hline & $\mathrm{HCO} 2$ & 33 & 3 & 1 & 0 & 2 & 61 \\
\hline & $\mathrm{HCO} 3$ & 23 & 1 & 0 & 0 & 1 & 54 \\
\hline
\end{tabular}

calculated based on hypergeometric test. The Benjamini and Hochberg method was used to adjust $p$-value. Significantly enriched GO term and KEGG pathway were selected under the following criteria: adjusted $p$-value $<0.05$.

The abundances of immune cells were estimated by CIBERSORTx web server and the LM22 signature matrix, which contains 547 genes distinguishing 22 human hematopoietic cell phenotypes. TPM was used for normalizing gene expression levels. B-mode batch correction was enabled and quantile normalization was disabled.

BCR and TCR clonotypes were recovered from RNA-seq data using Mixcr (v.3.0.12). "Analyze Shotgun", a single command integrating a complicated execution pipelines for RNA-seq data, was used with parameters "impute-germline-on-export" and "only-productive". Unique clonotype was defined as BCR/TCR with specific CDR3 nucleotide sequence, V/J segments, and hypermutations.

\section{qRT-PCR}

Total RNAs of decidua tissues were extracted using Trizol (Invitrogen) according to manual instructions. Quantitative RT-PCR (qRT-PCR) was performed using the HiScriptII Supermix (Vazyme, Nanjing, China) following the manufacturer's instructions. Briefly, RNA was quantified using a Nanodrop One instrument (Thermo, MA, USA) and $1 \mu \mathrm{g}$ was used for reverse transcription using random primers. For qRTPCR, SYBR Green master mix and primers (final concentration at $200 \mathrm{nM}$ ) were used and results were analyzed in CFX Connect PCR detection system (Bio-Rad, CA, USA). Primers were designed according to a previous publication (22) for CCL8 and $G A P D H$, or using an open resource (www.ncbi.nlm.nih. gov/tools/primer-blast) for TRDV1, TRDV2, and TRDV3, whose sequences are listed in Supplementary Table S2. Expression levels were normalized to GAPDH and represented as fold change compared to the control $\left(2^{-\Delta \Delta \mathrm{Ct}}\right)$.

\section{Immunohistochemistry}

Paraffin sections were dewaxed by dimethylbenzene and rehydrated by gradually reduced concentration of ethanol. Then, the slides were boiled in AR6 (antigen retrieval solution) for $15 \mathrm{~s}$ and incubated for $15 \mathrm{~min}$, followed by cooling in ice water for $20 \mathrm{~min}$. Endogenous peroxidase activity was blocked with $4 \%$ hydrogen peroxide for $15 \mathrm{~min}$ at room temperature, and nonspecific binding was blocked with $1 \%$ bovine serum albumin/PBS (1\% BSA) solution for $1 \mathrm{~h}$; 1:150 diluted primary mouse antihuman $\mathrm{TCR} \gamma \delta \mathrm{mAb}(\mathrm{H}-41, \mathrm{Abcam})$ in $1 \% \mathrm{BSA}$ was used for overnight incubation at $4^{\circ} \mathrm{C} ; 1: 200$ diluted HRP-conjugated goat anti-mouse IgG mAb (Akoya Biosciences) in 1\% BSA was used as secondary antibody for $1 \mathrm{~h}$ incubation at $37^{\circ} \mathrm{C}$. The HRP activity was revealed with ready-to-use 3,3-diaminobenzidine tetrahydrochloride $(\mathrm{DAB})$ for $3 \mathrm{~min}$, and nuclei was slightly counterstained with hematoxylin. The slides were always washed three times between each step with $1 \%$ Tween 20 and $0.3 \%$ Triton X-100 in PBS. After staining, samples were dehydrated by gradually increased concentration of ethanol. Finally, the slides were mounted with resinene for microscope observation. The images were obtained by DSY2000X (UOP, Chongqing, China).

\section{Multicolor IHC (mIHC)}

mIHC was performed using Opal 7-Color Manual IHC Kit (Akoya Biosciences, DE, USA) following the manufacturer's instructions. Briefly, dewaxed and rehydrated sections were antigen retrieved and blocked for endogenous peroxidase and Fc receptor using the same procedure as described in the Immunohistochemistry section. The samples were incubated in mouse anti-human TCR $\gamma \delta \mathrm{mAb}(\mathrm{H}-41$, Abcam, 1:150 diluted) for 1 hour at $37^{\circ} \mathrm{C}$, HRP-conjugated goat anti-mouse IgG $\mathrm{mAb}$ (1:200 diluted) for $30 \mathrm{~min}$ at $37^{\circ} \mathrm{C}$, Opal520 fluorescein (1:100 diluted in amplification buffer) for $10 \mathrm{~min}$ at $37^{\circ} \mathrm{C}$, successively. The nonspecific staining was removed by repeating the procedure of antigen-repair through AR6. The samples were then incubated with mouse anti-human CD107a mAb (H4A3, $\mathrm{BD}, 1: 100$ diluted) for $1 \mathrm{~h}$ at $37^{\circ} \mathrm{C}$, HRP-conjugated goat antimouse IgG $\mathrm{mAb}$ (1:200 diluted) for $30 \mathrm{~min}$ at $37^{\circ} \mathrm{C}$, and Opal620 fluorescein (1:100 diluted in amplification buffer) for $10 \mathrm{~min}$ at $37^{\circ} \mathrm{C}$, successively. The slides were always washed three times between each step with $1 \%$ Tween 20 and $0.3 \%$ Triton X-100 in PBS. After staining, samples were stained for cellular DNA with DAPI and mounted with Fluoromount-G (SouthernBiotech, AL, USA). The images were obtained by DSY2000X (UOP, Chongqing, China). The cells with green fluorescence were counted, in which red fluorescence was checked for each cell, and finally the frequency of CD107a-expressing cells in decidual $\gamma \delta \mathrm{T}$ cells was assessed in a blinded manner by two independent pathologists.

\section{Statistical Analysis}

Statistical analyses were performed with GraphPad Prism software (Version 6.0, GraphPad Software Inc.). Throughout the study, $n$ refers to the number of subjects where every subject is one data point. Unpaired two-group comparisons were done with Mann-Whitney $U$-test. Paired two-group comparisons were done with Wilcoxon matched-pairs signed rank test. In figures, ${ }^{* *} p<0.001,{ }^{* *} p<0.01$, and ${ }^{*} p<0.05$. In tables, 
continuous variables were described as mean \pm SD and compared using two-tailed Student's $t$-test or Mann-Whitney $U$-test for two groups depending on distribution.

\section{RESULTS}

\section{Unchanged Frequency of $\gamma \delta \mathrm{T}$ Cells but Increased PD1 Expression on $\gamma \delta$ T Cells in Pregnant RSA Patients}

Previous reports have shown that the frequency of $\gamma \delta \mathrm{T}$ cells changed during pregnancy in the peripheral blood of RSA patients $(16,17,23-27)$, while other studies did not support this notion $(28,29)$. We therefore sought to examine this issue in our cohort (see Study Participants section). Peripheral blood samples were stained for $\gamma \delta \mathrm{T}$ cells by flow cytometry, and the gating strategy was shown (Supplementary Figure S1A). The frequencies of $\alpha \beta \mathrm{T}$ and $\gamma \delta \mathrm{T}$ cells in all T cells were comparable between all four groups (Figure 1A), so were the frequencies of $\gamma \delta \mathrm{T}$ subsets (i.e., $\mathrm{V} \delta 1^{+}$and $\mathrm{V} \delta 2^{+}$cells) in all $\mathrm{T}$ cells (Figure 1B) or in $\gamma \delta$ T cells (Supplementary Figure S1B). When the ratios of different $\gamma \delta \mathrm{T}$-cell subsets were compared, the ratio of $\mathrm{V} \delta 2^{+}$to ${\mathrm{V} \delta 1^{+}}^{+}$cells tended to decrease in RSA patients, which did not reach significant difference (Supplementary Figures S1C, D). These results indicated the unchanged frequency of $\gamma \delta \mathrm{T}$ cells among different groups in our cohort.

We further examined $\mathrm{T}$ cells and their subsets for the expression of PD1, a molecule mainly expressed on activated $\mathrm{T}$ cells and was frequently used as an activation and exhaustion marker for immune cells (30). We found an increased PD1 expression on $\alpha \beta \mathrm{T}$ cells in the RSA-P group compared to the RSA-UP group, whereas PD1 expression on $\gamma \delta$ T cells were not significantly different between these two groups, despite the fact that we did notice an increased tendency ( $p=0.109$, Figure 1C). We went on to determine the expression of PD1 on $\gamma \delta$ T-cell subsets and found that the frequency of $\mathrm{PD}^{+} \mathrm{V} \delta 2^{+}$cells was increased in the RSA-P group compared to the RSA-UP group (Figure 1D and Supplementary Figure S1E).

Taken together, our results indicated that the frequency of $\gamma \delta$ $\mathrm{T}$ cells was unchanged in RSA patients compared to healthy controls and was relatively stable during physiological and pathological pregnancy. However, PD1 expression on $\mathrm{V} \delta 2^{+}$ cells and $\alpha \beta$ T cells was significantly increased in RSA patients during pregnancy (RSA-P vs. RSA-UP). Thus, the delicate control of PD1 expression on these two cell populations may be required for successful pregnancy.

\section{Increased Cytotoxicity of $\gamma \delta \mathrm{T}$ Cells in the RSA-P Group}

It was reported that decidual $\gamma \delta \mathrm{T}$ cells in early pregnancy expressed cytotoxic molecules such as perforin, granzyme A (GZMA), granzyme B (GZMB), FasL, and Granulysin (20), which were potentially detrimental to the fetus; we therefore explored cytotoxicity-related phenotypes of $\gamma \delta \mathrm{T}$ cells to reveal the functional state of $\gamma \delta \mathrm{T}$ cells during spontaneous abortion. For this purpose, PBMCs were obtained from the blood and stained for the expression of GZMB, perforin, and CD107a on $\gamma \delta$ $\mathrm{T}$ cells/subsets. The gating strategy is shown in Supplementary Figure S2A. There was no significant difference between four groups in terms of the frequencies of $\mathrm{GZMB}^{+}$(Figure 2A), perforin $^{+}$(Figure 2A), and $\mathrm{GZMB}^{+}$perforin ${ }^{+}$double-positive cells (Supplementary Figure S2B) in both $\mathrm{V} \delta 1$ and $\mathrm{V} \delta 2$ cells.

Interestingly, we observed an increased tendency regarding the frequency of CD107a ${ }^{+}$cells in V $\delta 2$ cells in un-pregnant RSA patients compared to un-pregnant controls (RSA-UP vs. H-UP, $p=0.0565$, Figure 2B), and the difference was more evident in the RSA-P vs. H-P comparison ( $p<0.01$, Figure 2B). CD107a is a molecule exported to the surface of cytotoxic cells upon cell degranulation (31); therefore, increased expression of CD107a can reflect the elevated killing capability of $\gamma \delta$ T cells. Together, our results indicated that even without the increased expression of GZMB and perforin, $\gamma \delta$ T cells in RSA patients might still have elevated cytotoxicity by increasing their CD107a expression and contribute to the recurrent spontaneous abortion.

\section{Increased IL-17A-Secreting V $\delta 2^{+}$Cells but Not IL-4-Secreting V $\delta 2^{+}$Cells in Peripheral Blood From RSA Patients During Pregnancy}

Both decidual and peripheral $\gamma \delta \mathrm{T}$ cells have been reported to exhibit Th1-, Th2-, and Th17-like phenotypes, the balance of which during gestation has been suggested to be related to the outcome of pregnancy $(18,26,32,33)$. Therefore, we next set out to examine the balance of these cytokine-defined $\gamma \delta$ T-cell subsets in RSA patients and healthy controls. PBMCs were obtained from the blood and stimulated with PMA/Ionomycin/Brefeldin A for $5 \mathrm{~h}$ before being stained with antibodies against IFN $\gamma$ and IL-4 or TNF $\alpha$ and IL-17A, and the gating strategy is shown in Supplementary Figure S3A using a representative sample. There was no significant difference regarding the frequency of IFN $\gamma^{+}$and $\mathrm{TNF} \alpha^{+}$cells in $\mathrm{V} \delta 1^{+}$and $\mathrm{V} \delta 2^{+} \gamma \delta$ T cells among four different groups (Supplementary Figures S3B, C). However, the IL-4-secreting $\mathrm{V} \delta 2^{+}$cells were significantly increased in pregnant healthy controls compared to un-pregnant controls (HC-P vs. HC-UP), whereas the same cells were not different in the comparison between the RSA-P and RSA-UP groups (Figure 3A). On the contrary, increased IL-17A-secreting $\mathrm{V} \delta 2^{+}$ cells were only evident in the RSA-P vs. RSA-UP comparison, but not in the HC-P vs. HC-UP comparison (Figure 3B). Interestingly, the IL-17A-secreting $\mathrm{V} \delta 2^{+}$cells also tended to be increased in the RSA-P group compared to the HC-P group (Figure 3B). Together, our results suggested that the upregulation of IL-4-secreting $\mathrm{V} \delta 2^{+}$cells and the relatively stable frequency of IL-17A-secreting $\mathrm{V} \delta 2^{+}$cells may be required for maintaining healthy pregnancy, whereas the dysregulation of these cells could contribute to the occurrence of RSA.

\section{Inflammatory Microenvironment in the Decidua of RSA Patients}

To explore the changes of local microenvironment in the fetomaternal interface during early pregnancy in RSA, we next examined the transcriptional profiles of the decidua tissue by 

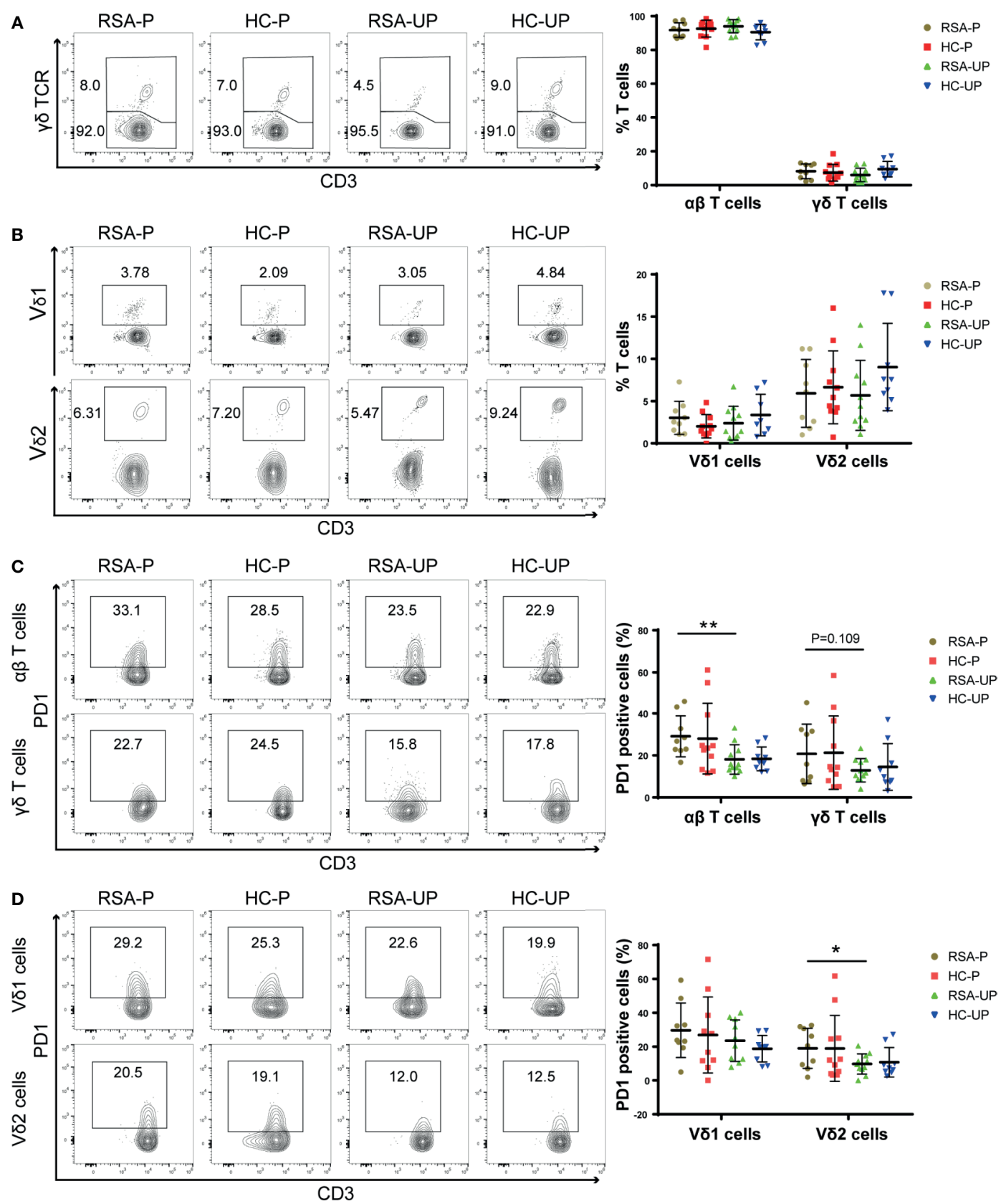

FIGURE 1 | The frequencies of T-cell subsets and their PD1 expression in the peripheral blood of RSA patients and healthy controls with or without pregnancy. Peripheral blood samples from four groups were stained for T-cell subsets and PD1 expression. (A) The frequencies of $\alpha \beta T$ cells and $\gamma \delta T$ cells in all T cells. (B) The frequencies of $V \delta 1^{+}$cells and $V \delta 2^{+}$cells in total T cells. (C) PD1 expression on $\alpha \beta T$ cells and $\gamma \delta T$ cells. (D) PD1 expression on V $\delta 1^{+}$cells and $V \delta 2^{+}$cells gated from total T cells. Left, representative flow cytometry plots; right, statistical data show mean \pm s.e.m. Statistical analyses using MannWhitney U-test for the same cells among different groups. Differences are indicated: ${ }^{* *} p<0.01$ and ${ }^{*} p<0.05$. RSA-P, RSA pregnant, $n=10$; HC-P, healthy pregnant, $n=11$; RSA-UP, RSA unpregnant, $n=11$; HC-UP, healthy unpregnant, $n=10$.

RNA sequencing using samples from three RSA patients and three healthy controls (Table 2). Principal component analysis was used to reveal the overall gene expression pattern for each sample (Supplementary Figure S4A). Differential gene expression analysis for the RSA-P and HC-P groups found that
44 genes were differentially expressed (Figures 4A, B), of which the CCL8 gene was upregulated in the RSA-P group. The increased CCL8 expression in the RSA-P group was further confirmed by qRT-PCR using more samples (Figure 4C), suggesting the potential proinflammatory role of CCL8 

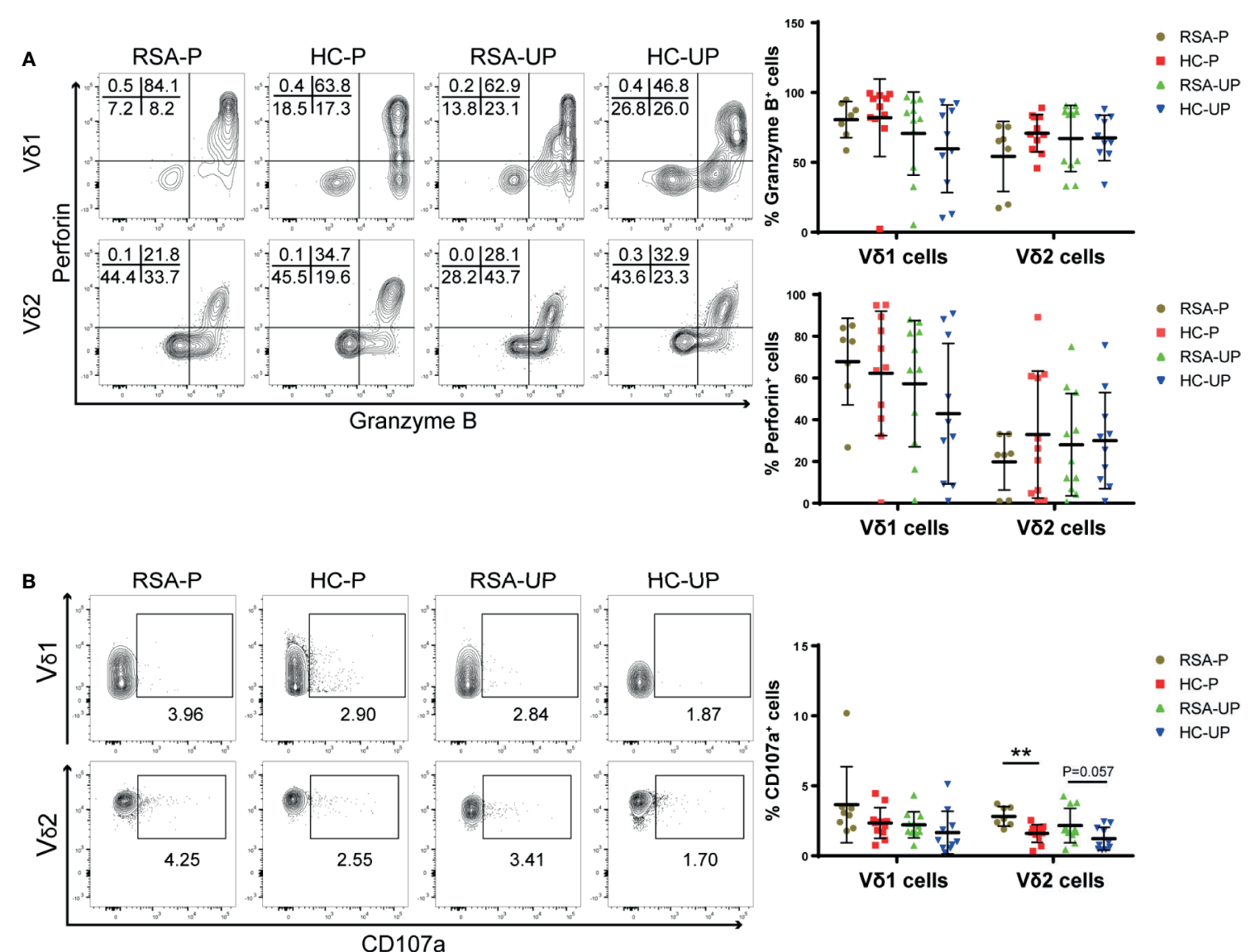

FIGURE 2 | The frequencies of perforin ${ }^{+}, \mathrm{GZMB}^{+}$, and $\mathrm{CD} 107 \mathrm{a}^{+}$cells in peripheral $\gamma \delta \mathrm{T}$ cells in RSA patients and healthy controls with or without pregnancy. PBMCs were obtained from peripheral blood of each subject and directly stained for membrane CD107a as well as intracellular perforin and GZMB. (A) The frequencies of $G Z M B^{+}$and perforin ${ }^{+}$cells in $V \delta 1^{+}$cells and $V \delta 2^{+}$cells from four groups. (B) The frequencies of $C D 107 a^{+}$cells in $V \delta 1^{+}$cells and $\mathrm{V} \delta 2^{+}$cells from four groups. Left, representative flow cytometry plots; right, statistical data show mean \pm s.e.m. Statistical analyses using Mann-Whitney $U$-test among different groups. Differences are indicated: ${ }^{* *} p<0.01$. RSA-P, RSA pregnant, $n=10$; HC-P, healthy pregnant,

$n=11 ;$ RSA-UP, RSA unpregnant, $n=11$; HC-UP, healthy unpregnant, $n=10$.

molecule in the feto-maternal interface during pathological pregnancy by recruiting immune cells. Of note, the differently expressed genes were mainly enriched into the glycolysis pathway (Figure 4D and Supplementary Figure S4B), which might be caused by the majority of stroma cells in the decidua, as determined by hematoxylin-eosin staining (data not shown). Since the upregulated CCL8 could result in the increased recruitment of multiple types of immune cells to exaggerate the inflammatory conditions, the distribution of immune cells was further analyzed by the CIBERSORT algorithm. This analysis demonstrated that $\mathrm{CD} 8^{+} \mathrm{T}$ cells and M2 macrophages were increasingly distributed in the RSA-P group (Figure 4E and Supplementary Figure S4C).

In sum, our transcriptomic analysis indicated that the upregulated expression of CCL8 increased infiltration of CD8 ${ }^{+}$ T cells and M2 macrophages, and more vigorous glycolysis may orchestrate to promote an inflammatory microenvironment in the feto-maternal interface in RSA patients.

\section{Higher CD107a Expression on Decidual $\gamma \delta$ T Cells in RSA Patients}

Since $\gamma \delta \mathrm{T}$ cells could either secrete CCL8 $(34,35)$ or respond to CCL8 by expressing its receptors such as CCR1 (36), CCR2 (36-38), CCR3 (39), and CCR5 (40), we therefore examined the decidual presence of $\gamma \delta \mathrm{T}$ cells in the RSA-P and HC-P groups by IHC. $\gamma \delta \mathrm{T}$ cells can be found in the decidua of both RSA-P and HC-P women, but there was no significant difference regarding the proportion of $\gamma \delta \mathrm{T}$ cells between these two groups, and the infiltration of this cell was relatively low when using tumor samples as positive control (Figure 5A). We also recovered the sequence information of BCR and TCR chains from our RNA-seq data; no difference was found in terms of the numbers of recovered TRD and TRG chains, which reflect the diversity of TCR- $\gamma$ and $-\delta$ chains, respectively (Figure S5A). TRD was further analyzed by qRT-PCR using more samples, and no difference was found as well (Figure S5B). Next, to determine if the expression of the cytotoxic molecule CD107a is 

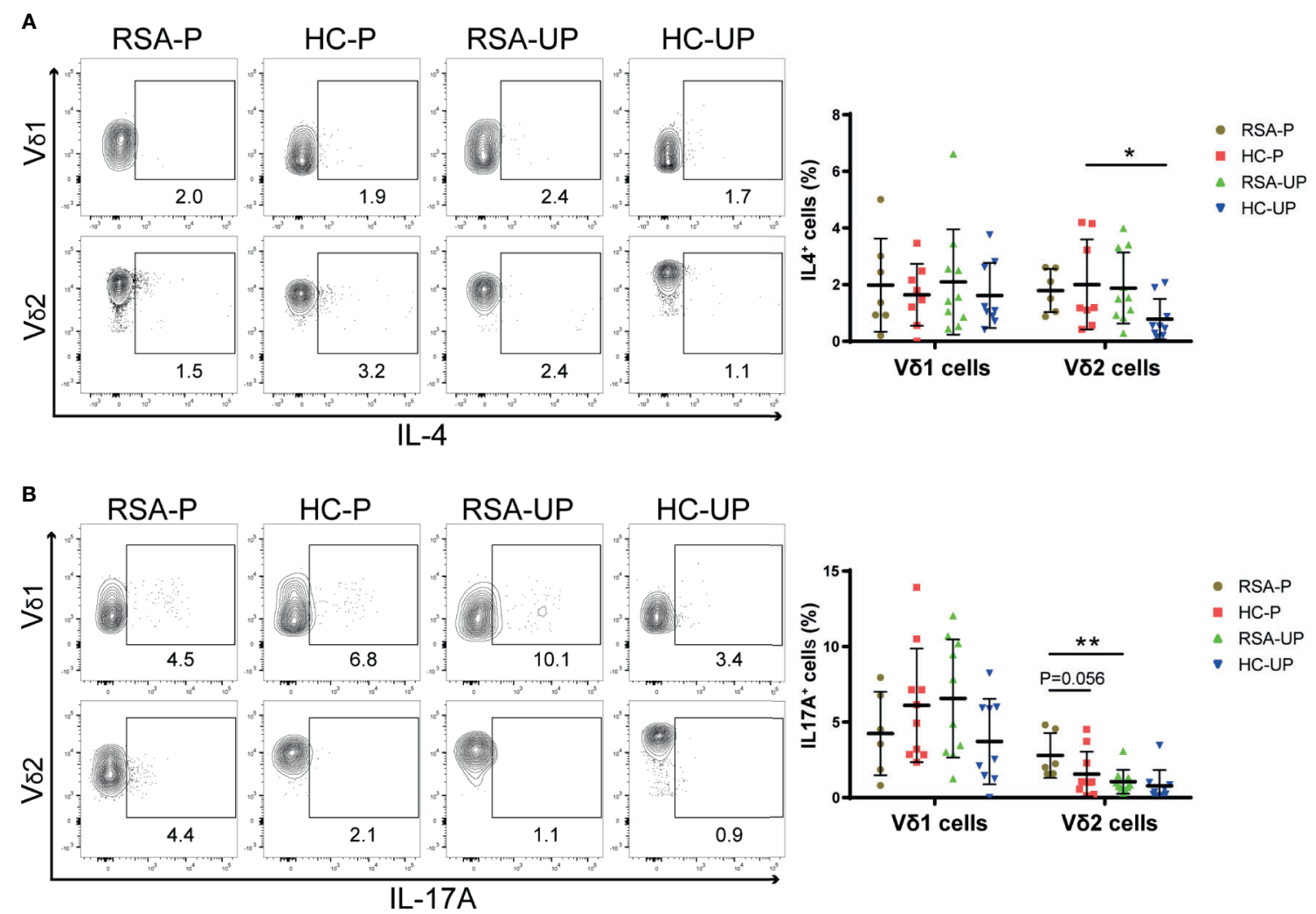

FIGURE 3 | The cytokine profiles of $V \delta 1^{+}$and $V \delta 2^{+} \gamma \delta$ T cells in the peripheral blood of RSA patients and healthy controls with or without pregnancy. PBMCs were obtained from peripheral blood of each subject and stimulated with PMA/lonomycin/Brefeldin A for $5 \mathrm{~h}$ before being stained for intracellular cytokines. (A) The frequencies of IL-4-secreting cells in $V \delta 1^{+}$cells and $V \delta 2^{+}$cells from four groups. (B) The frequencies of IL-17A-secreting cells in $V \delta 1^{+}$cells and $V \delta 2^{+}$ cells from four groups. Left, representative flow cytometry plots; right, statistical data show mean \pm s.e.m. Statistical analyses using Mann-Whitney U-test among different groups. Differences are indicated: ${ }^{* *} p<0.01$, and ${ }^{*} p<0.05$. RSA-P, RSA pregnant, $n=10$; HC-P, healthy pregnant, $n=11$; RSA-UP, RSA unpregnant, $n=11$; HC-UP, healthy unpregnant, $n=10$.

also upregulated in the decidua of RSA-P patients, especially on $\gamma \delta$ $T$ cells, as indicated by our previous finding in peripheral blood, we stained for the expression of CD107a and $\gamma \delta$ T cells simultaneously using multicolor IHC. Our result showed a higher expression of CD107a in RSA-P patients compared to HC-P controls (Figure 5B and Supplementary Figure S5C), and the co-localization of CD107a and $\gamma \delta \mathrm{T}$ cells can be found in RSA-P patients but rarely in healthy controls. Together, although decidual $\gamma \delta \mathrm{T}$ cells had similar diversity in RSA-P and HC-P women, these cells may increase their CD107a expression during RSA and thus contribute to spontaneous abortion.

\section{DISCUSSION}

Previous studies have reported the increased $\gamma \delta \mathrm{T}$ cells in the peripheral blood during normal pregnancy $(17,23,24,27)$, suggesting that these cells are important for successful pregnancy $(24,25)$. However, no consistent conclusion has been reached regarding the alteration of $\gamma \delta \mathrm{T}$ cells in RSA patients compared to healthy controls, with some investigations showing the increase of these cells in RSA $(16,41)$, whereas others provide data that do not support this notion $(28,42)$. This discrepancy disappeared when examining $\gamma \delta \mathrm{T}$ cell subsets, since the increased frequency of $\mathrm{V} \delta 2+$ cells, which is the predominant subsets in peripheral $\gamma \delta \mathrm{T}$ cells, was unanimously observed in RSA patients (43). Therefore, we examined these issues in our cohort, which included 42 RSA patients and healthy controls with or without pregnancy (see Study Participants section). We found that the frequency of $\gamma \delta \mathrm{T}$ cells and the V $\delta 1 / \mathrm{V} \delta 2$ ratio were comparable among the four different groups. Thus, our results do not support the notion that the frequencies of peripheral $\gamma \delta \mathrm{T}$ cells and their subsets are significantly changed during early pregnancy in either RSA patients and healthy controls. However, further investigations including more subjects are required to confirm these results. One interpretation for this discrepancy might be the dynamic distribution of $\gamma \delta \mathrm{T}$ cells during pregnancy $(43,44)$. Alternatively, it could be the phenotype but not the number of $\gamma \delta$ $\mathrm{T}$ cells/subsets that is actually altered in RSA.

To investigate the phenotypic changes of peripheral $\gamma \delta \mathrm{T}$ cells and their subsets in RSA, we next examined the PD1 expression on maternal circulating $\gamma \delta \mathrm{T}$ cells/subsets and other T cells and 

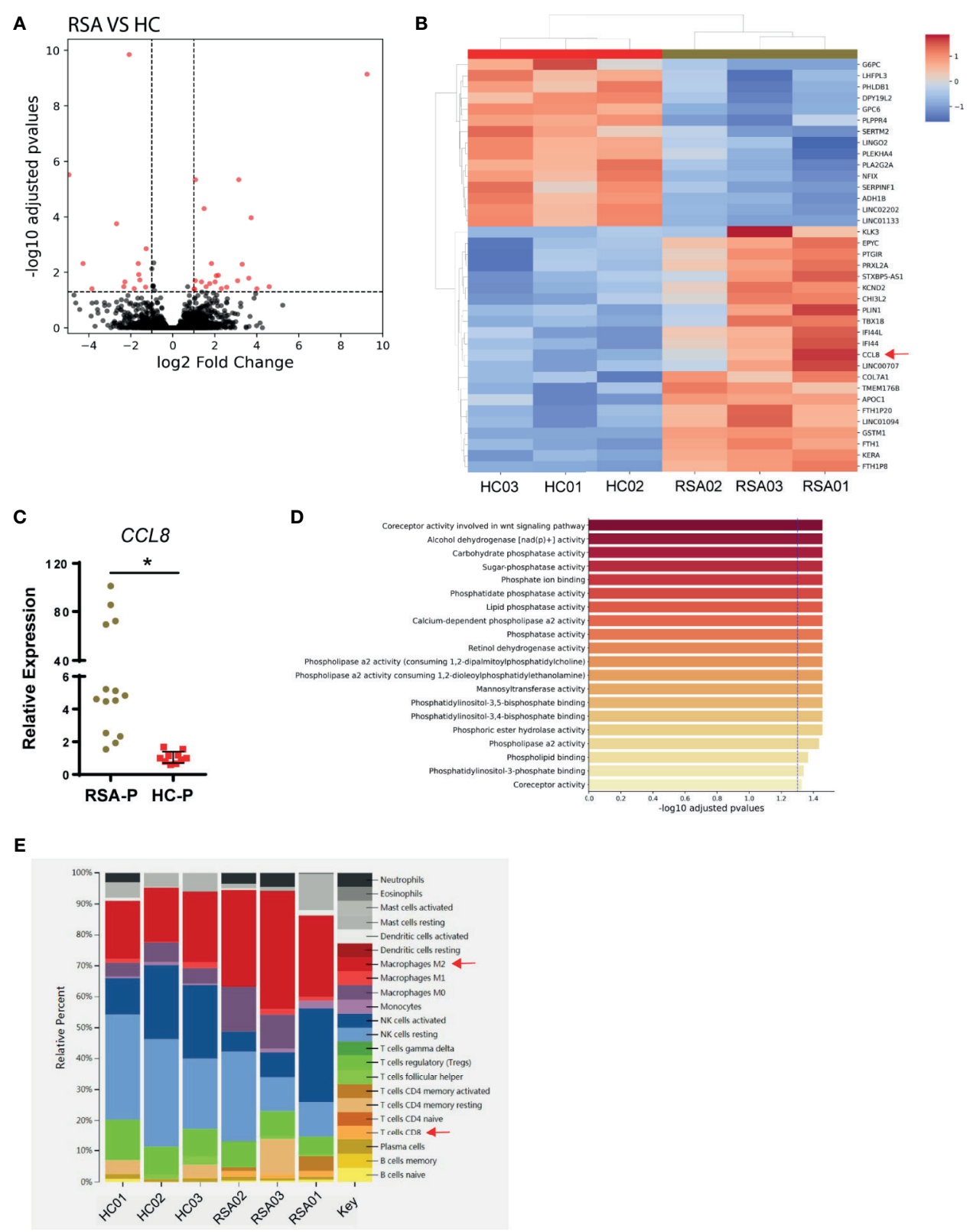

FIGURE 4 | Transcriptomic analysis of decidual samples from RSA-P patients and HC-P subjects. Bulk RNA-seq was performed with decidual samples from RSA-P patients $(n=3)$ and HC-P subjects $(n=3)$. (A) Volcano plots illustrating differentially expressed genes (DEGs) between RSA-P patients and HC-P controls. (B) Heatmap showing DEGs between RSA-P and HC-P patients. (C) qRT-PCR analysis for CCL8 expression in RSA-P and HC-P decidua with 14 samples in each group. (D) GO analysis for the DEGs. (E) CIBERSORT analysis for the immune cells. Statistical data show mean \pm s.e.m. Statistical analyses using Mann-Whitney U-test among different groups. Differences are indicated: ${ }^{*} p<0.05$.

found that elevated PD1 expression was evident on $\mathrm{V} \delta 2^{+}$cells and $\alpha \beta$ T cells in the RSA-P group compared to that in the RSAUP group. However, the increased PD1 expression on these cells was not observed in the HC-P vs. HC-UP comparison or in the RSA-P vs. HC-P comparison like others (42), suggesting that $\mathrm{V} \delta 2^{+}$cells and $\alpha \beta \mathrm{T}$ cells might upregulate their PD1 expression during pathological pregnancy. PD1 is a molecule expressed upon T-cell activation, which then acts as a checkpoint to prevent exaggerated $\mathrm{T}$-cell activation through interacting with its ligand, PD-L1 or PD-L2 (45). In the past few decades, PD1expressing $\mathrm{T}$ cells have been well-established as an exhausted $\mathrm{T}$ cell population with defective function generated during chronic viral infection and tumor development $(46,47)$. Accordingly, targeting these cells by PD1 blockade has resulted in great clinical success in cancer immunotherapy for a variety of cancer types (48). Not surprisingly, $\mathrm{PD}^{+} \alpha \beta$ T cells and $\gamma \delta \mathrm{T}$ cells were also 
A

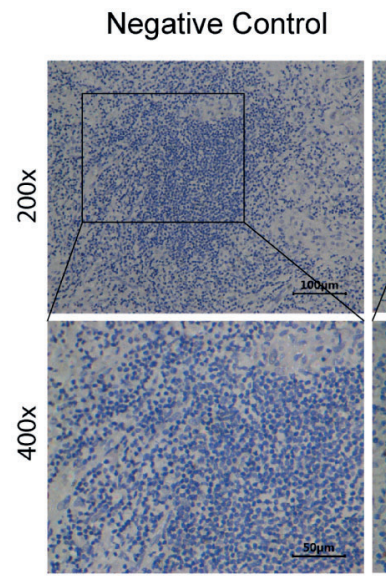

B
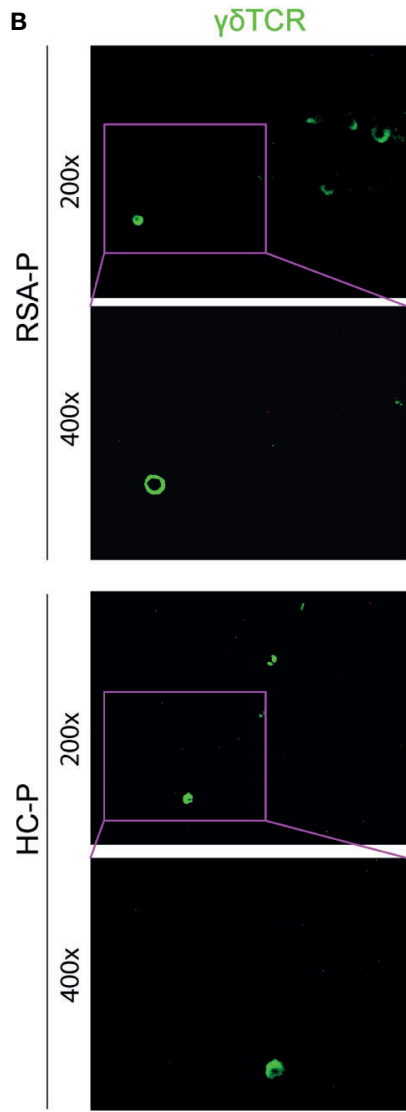

Positive Control

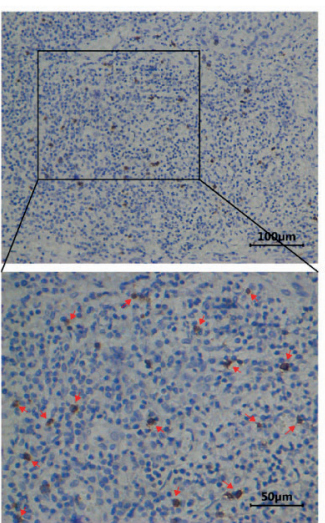

CD107a
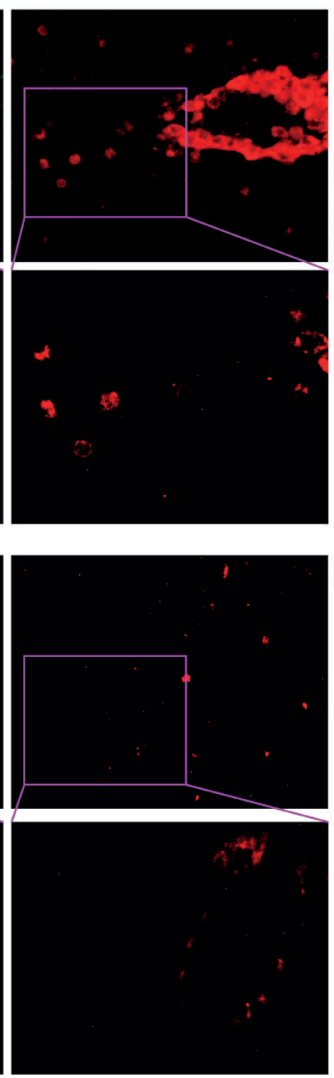

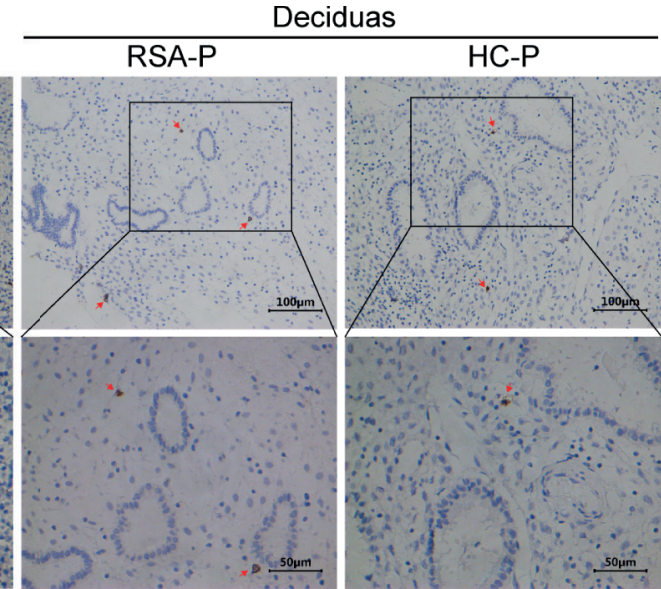

DAPI
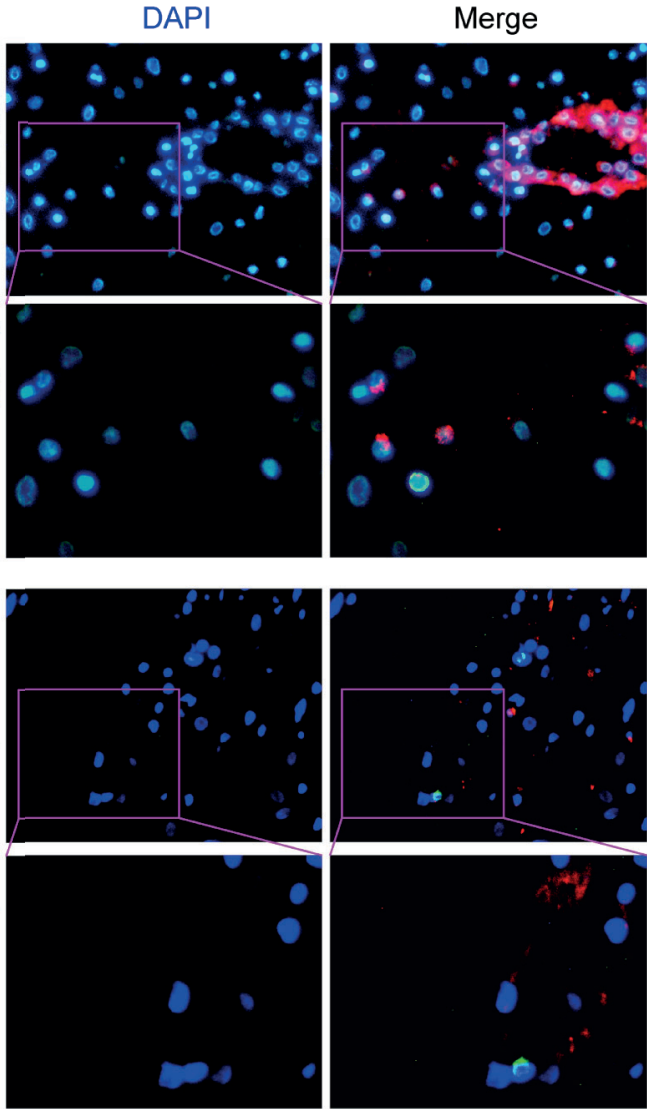

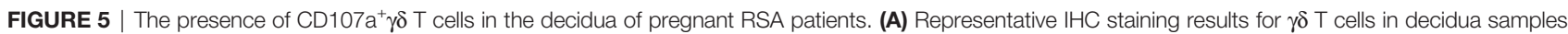
from an RSA-P patient and a H-P control (right); tumor samples were used as negative and positive control. Positive staining was indicated by the red arrow.

(B) Representative $\mathrm{mlHC}$ staining results of $\gamma \delta \mathrm{TCR}, \mathrm{CD} 107 \mathrm{a}$, and DAPI with decidua samples from an RSA-P patient and a H-P control. $\gamma \delta$ TCR was labeled with Opal 520 (green), CD107a was labeled with Opal 620 (red), and the nuclei were stained with DAPI (blue).

identified during pregnancy and were often suggested as exhausted $\mathrm{T}$ cells that are protective for normal pregnancy (49). However, $\mathrm{PD}^{+} \mathrm{T}$ cells may contain not only exhausted $\mathrm{T}$ cells, but also non-exhausted $\mathrm{T}$ cells that are activated. An early study reported that upon stimulation with viral antigen, $\mathrm{PD} 1^{+} \mathrm{T}$ cells exhibited polyfunctionality, as indicated by their capacity to produce TNF $\alpha$ and IFN $\gamma$ and express CD107a (50). PD1 expression was also frequently used as an activation marker for $\mathrm{T}$ cells in other investigations (50-52). Therefore, $\mathrm{PD}^{+} \mathrm{V} \delta 2^{+}$ cells and $\alpha \beta \mathrm{T}$ cells could simply be activated $\mathrm{T}$ cells with 
proinflammatory function, and their increase in RSA may suggest the pathogenicity of these cells in RSA. Nevertheless, further studies are warranted for examining the functionality of these $\mathrm{PD} 1^{+} \mathrm{T}$ cells, not only in the periphery blood but also in the decidua, to offer a precise understanding of the role of these cells in physiological and pathological pregnancy.

$\mathrm{V} \delta 2^{+}$cells are the major subpopulation of $\gamma \delta \mathrm{T}$ cells in the periphery. It has been reported that these $\gamma \delta \mathrm{T}$ cells are able to utilize perforin-GZMB, Fas-FasL, and TRAIL pathways to kill target cells upon activation (53). The upregulation of PD1 on these cells in RSA prompted us to test whether they also have altered cytotoxicity. For this purpose, we compared the expression of cytotoxicity-related molecules (i.e., perforin, GZMB, and CD107a) on periphery $V \delta 2^{+}$cells from RSA patients and health controls with or without pregnancy. We found that increased CD107a expression was evident on $\mathrm{V} \delta 2^{+}$ cells in RSA-P patients in comparison to that in H-P subjects. Interestingly, the frequency of the same cell also showed an increased tendency in un-pregnant RSA patients compared to un-pregnant controls. Together, these results suggest that cytotoxic $\mathrm{CD} 107 \mathrm{a}^{+} \mathrm{V} \delta 2^{+}$cells could be pathogenic in RSA, and further increased frequency of these cells may lead to the failure of pregnancy. However, we failed to find any difference in all four groups compared in terms of the expression of perforin and GZMB on $\mathrm{V} \delta 2^{+}$cells and $\mathrm{V} \delta 1^{+}$cells. The differential expression patterns of the above two molecules and CD107a could be due to the different detection methods used. For perforin and GZMB, the two main cytotoxic molecules that are stored in the intracellular granules of cytotoxic cells (54) and are released upon stimulation (55), intracellular staining was used in this study according to the protocol used by numerous investigations (54), the result of which can only reflect the cytotoxic potential of cytotoxic cells. However, for CD107a, a protein constitutively expressed on the lysosomal membrane and exported to the cell membrane upon stimulation, we used direct surface staining for ex vivo cells without any in vitro stimulation (56-58); thus, our ex vivo measurement can faithfully recapitulate the in vivo expression pattern of CD107a. Of note, we did not find any change of CD107a expression on peripheral $\gamma \delta \mathrm{T}$ cells during normal pregnancy (i.e., HP vs. H-UP, Figure 2B), which is different from a recent study by Norenberg et al. (59). Using an in vitro stimulation protocol with ionomycin and PMA, they found that CD107a expression on peripheral $\gamma \delta \mathrm{T}$ cells was increased on $\mathrm{CD}^{-} \gamma \delta \mathrm{T}$ cells in the first trimester and decreased slowly in the second as well as the third trimester. Given the low proportion of $\mathrm{CD}_{5} 6^{+} \gamma \delta \mathrm{T}$ cells and the high frequency of $\mathrm{V} \delta 2^{+}$ cells among peripheral $\gamma \delta \mathrm{T}$ cells, the CD107a expression on total $\mathrm{V} \delta 2^{+}$cells was very likely increased as well during healthy pregnancy in their study. The distinct results by this investigation and ours could again be attributed to the aforementioned different methods used for detecting the surface expression of CD107a. Interestingly, Norenberg et al. also determined the co-expression of CD107a and PD1 on $\gamma \delta \mathrm{T}$ cells and argued that PD1 expression could represent a negative feedback mechanism used by cytotoxic CD107a ${ }^{+} \gamma \delta \mathrm{T}$ cells to downregulate their cytotoxicity and secure the success of pregnancy. Nevertheless, the co-expression of CD107a and PD1 on $\gamma \delta \mathrm{T}$ cells should be measured in the future investigation to test this hypothesis.

Distinct from peripheral blood, the feto-maternal interface (i.e., the decidua) harbors a very unique immune milieu (60). Furthermore, CD107a expression was reported to be lower in decidua $\gamma \delta \mathrm{T}$ cells than that in circulating $\gamma \delta \mathrm{T}$ cells (61); therefore, we then interrogate if CD107a is similarly overexpressed on decidua $\gamma \delta \mathrm{T}$ cells as on peripheral $\gamma \delta \mathrm{T}$ cells in RSA. As revealed by IHC, $\gamma \delta \mathrm{T}$ cells can be found in the decidua of both RSA-P patients and H-P controls at similar frequency (Figure 5A). However, when $\gamma \delta \mathrm{T}$ cells and CD107a were simultaneously stained by $\mathrm{mIHC}, \mathrm{CD} 107 \mathrm{a}$-expressing $\gamma \delta \mathrm{T}$ cells could be readily detected in RSA-P patients but rarely in $\mathrm{H}$ $\mathrm{P}$ controls (Figure 5B). Of note, CD107a-expressing non- $\gamma \delta \mathrm{T}$ cells were also more frequently observed in RSA-P patients than in H-P controls (Figure 5B). Collectively, our results indicated that CD107a-expressing $\gamma \delta \mathrm{T}$ cells in both periphery and decidua might be pathogenic in RSA, and other cytotoxic cells may also contribute.

Historically, Th1/Th2 imbalance has been frequently used to explain the immune puzzle of pregnancy, during which maternal immune system is inevitably aware of semi-allogenic fetal antigens without rejecting the conceptus (62). According to this paradigm, maternal immune system should be adapted to be Th2 biased to prevent allorejection of the conceptus. In parallel to $\alpha \beta$ T cells, $\gamma \delta$ T cells can also be classified into Th1-, Th2-, Th17-, and Treg-like subsets according to their distinct cytokine profiles (63-66). Therefore, it is not totally surprising that the same paradigm was also applied in interpreting the role of $\gamma \delta \mathrm{T}$-cell subsets in physiological and pathological pregnancy. For example, various studies have reported the Th2 bias in the decidual $\gamma \delta \mathrm{T}$ cells characterized by secreting TGF $\beta$ and IL-10 (18), suggestive of their importance in maintaining successful pregnancy. On the contrary, Th1- and Th17-like $\gamma \delta \mathrm{T}$ cells were found to be higher in RSA patients than that in healthy controls $(17,67,68)$, and so was the Th1/Th2 ratio (69), indicating the pathogenic role of Th1- and Th17-like $\gamma \delta$ T cells in RSA. In the present study, higher frequency of IL-4-secreting V $\delta 2$ cells was only found in the HC-P vs. H-UP comparison, but not the RSA-P vs. RSA-UP comparison. This difference in IL-4-secreting V $\delta 2$ cells was in stark contrast to that in IL-17A-secreting V $\delta 2$ cells, the upregulation of which was only observed in the RSA-P vs. RSA-UP comparison, but not in the HC-P vs. H-UP comparison. Thus, our results are in agreement with previous publications in suggesting the pathogenic role of IL$17 \mathrm{~A}$-secreting $\gamma \delta \mathrm{T}$ cells and the protective role of IL-4-secreting $\gamma \delta$ T cells during pregnancy (70-72), and further specify that these cells belong to the V $\delta 2$ compartment. Of note, we did not find any difference between groups regarding the frequencies of TNF $\alpha$ - and IFN $\gamma$-secreting V $\delta 2$ cells, which were reported as Th1-like and suggested to be pathogenic in RSA (69). The reason could be that the frequencies of these cells are already very high (with the median of $89.31 \%$ and $94.72 \%$ for TNF $\alpha$ - and IFN $\gamma$-secreting V $\delta 2$ cells, respectively) (Supplementary Figures S3B, C) in unpregnant healthy controls from our cohort; thus, further increase is very difficult to be observed in RSA patients. 
Therefore, further studies with more patients and controls are required to confirm this result.

The median frequency of $\mathrm{V} \delta 2$ cells in peripheral $\gamma \delta \mathrm{T}$ cells is $74.6 \%$ (range $4.5 \%-90.6 \%$ ), $84.3 \%$ (range $20.0 \%-96.4 \%$ ), $82.4 \%$ (range $42.9 \%-90.5 \%$ ), and $79.7 \%$ (range $50.0 \%-94.0 \%$ ) in the RSA-P, HC-P, RSA-UP, and HC-UP groups, respectively (Figure 1B), which is in accordance with previous publications that $\mathrm{V} \delta 2$ cells are the predominant subset of peripheral $\gamma \delta \mathrm{T}$ cells. We failed to find any difference between the four groups. However, we did find that the differentially expressed markers (i.e., PD1, CD107a, IL-4, and IL-17A) were only observed on V $\delta 2$ cells but not on V $\delta 1$ cells. Previous measurements of these markers were mostly limited to total $\gamma \delta$ T cells, and given the high frequency of $\mathrm{V} \delta 2$ cells in peripheral $\gamma \delta \mathrm{T}$ cells, our results are therefore not surprising and are in agreement with previous findings in examining total $\gamma \delta \mathrm{T}$ cells. Of note, we failed to find any differential expression of aforementioned markers among four groups on $\mathrm{V} \delta 1$ cells, the minor population of peripheral $\gamma \delta \mathrm{T}$ cells. These cells generally exhibited higher expression of PD1, perforin, and IL-17A, as well as lower IFN $\gamma$ and TNF $\alpha$ expression than $V \delta 2$ cells in our measurement (Supplementary Figures S6A-E). Interestingly, the differential capability in producing cytokines (i.e., IL-17A, IFN $\gamma$, and TNF $\alpha$ ) between V $\delta 1$ cells and V $\delta 2$ cells in RSA-UP, HC-P, and HC-UP groups disappeared in the RSA-P group, indicating that except for $\mathrm{V} \delta 2$ cells, the role of $\mathrm{V} \delta 1$ cells in pregnancy should be further studied in future investigations.

The presence of $\gamma \delta$ T cells at the feto-maternal interface is not new. It was reported that the $\gamma \delta \mathrm{T}$ cells are present in the endometrium of all mammals throughout pregnancy (14) and in the decidua of human (13), mouse (67), and sheep (73). Decidual $\gamma \delta \mathrm{T}$ cells were found to be dividing (74) and undergoing TCR recombination $(73,75,76)$. Moreover, the number of $\gamma \delta \mathrm{T}$ cells was growing with an activated phenotype $(15,73,77,78)$ during pregnancy, suggesting a protective role of decidual $\gamma \delta \mathrm{T}$ cells in pregnancy. However, the abundance of $\gamma \delta \mathrm{T}$ cells in decidua was not clear, with one study showing that there are numerous $\gamma \delta$ T cells making up $60 \%$ of all T cells (13), and the other one indicating the rare presence of these cells (79). We used the same method as the latter report (i.e., IHC) and found that there were only a few $\gamma \delta \mathrm{T}$ cells in both RSA patients and healthy subjects with pregnancy. The discordance could be partially explained by the high sensitivity of the TCR chain to fixation and freezing (74), which also prevented us from detecting $\mathrm{V} \delta 1$ cells and $\mathrm{V} \delta 2$ cells. Alternatively, RNA sequencing and qRT-PCR were used to detect $\gamma \delta$ T cells and TCR $\delta$-defined subsets, and no difference was found between the RSA-P and HC-P groups in terms of the frequencies of TCR- $\gamma$, $-\delta,-\delta 1,-\delta 2$, and $-\delta 3$ chains detected. However, we found that CCL8, a gene coding a chemokine with the capacity to recruit an array of inflammatory cells including $\mathrm{T}$ cells and macrophages, was upregulated in RSA-P patients compared to HC-P subjects. In addition, CIBERSORT analysis also revealed the increased infiltration of $\mathrm{CD}^{+} \mathrm{T}$ cells and M2 macrophages in RSA-P patients. Taken together, these results suggest an inflammatory environment in the feto-maternal interface during early pregnancy in RSA patients. The involvement of $\gamma \delta \mathrm{T}$ cells in this scenario is currently not clear, although it was reported that $\gamma \delta \mathrm{T}$ cells could secrete high amount of $\operatorname{CCL} 8(34,35)$ and also can be recruited by CCL8 through expressing corresponding receptors such as CCR1, CCR2, CCR3, and CCR5 (36-40). Therefore, the increased number of $\mathrm{CD} 107 \mathrm{a}^{+} \gamma \delta \mathrm{T}$ cells may also be implicated in CCL8-mediated inflammatory response in RSA either as secreting cells or as responder cells. Further studies utilizing $\mathrm{mIHC}$ and/or multicolor flow cytometry and an in vitro functional study are required to address this speculation.

In conclusion, through examining peripheral $\gamma \delta \mathrm{T}$ cells/ subsets and their phenotype, we found the increased expression of PD1 and CD107a, as well as higher frequency of IL-17A-secreting cells and lower frequency of IL-4-secreting cells in the compartment of $\mathrm{V} \delta 2$ cells in RSA patients during pregnancy, suggesting that the activated phenotype, increased cytotoxicity, and imbalanced cytokine profiles of peripheral V $\delta 2$ cells may lead to the occurrence of RSA. Furthermore, increased CD107a ${ }^{+} \gamma \delta \mathrm{T}$ cells could be detected in the decidua of RSA-P patients compared to that in the HC-P subjects, accompanied by upregulated CCL8 expression, as well as increased $\mathrm{CD}^{+}{ }^{+} \mathrm{T}$ cells and M2 macrophages infiltration, suggestive of the contribution of decidual $\gamma \delta$ T cells to the local inflammatory response in RSA. Thus, dysregulated $\gamma \delta$ T cells in the periphery and decidua might be a hallmark of RSA; future investigations along this line will provide insight into the role of these cells in the pathogenesis of RSA, and will eventually lead to the successful management of RSA patients by manipulating these cells.

\section{DATA AVAILABILITY STATEMENT}

The datasets presented in this study can be found in online repositories. The names of the repository/repositories and accession number(s) can be found below: NCBI GEO, accession no: GSE178535.

\section{ETHICS STATEMENT}

The studies involving human participants were reviewed and approved by the institute ethics committee of Tongji Hospital (Ref. No. TJ-C20180201). The patients/participants provided their written informed consent to participate in this study.

\section{AUTHOR CONTRIBUTIONS}

YH, WZ, QW, HW, LY, and YaZ designed the study and wrote the manuscript. YaZ and LY contributed equally to this work. In detail, YaZ is responsible for collecting the samples and performing flow cytometry. LY took the responsibilities for analyzing the FACS result and performing the IHC. JX, JL, YiZ, QK, and PZ participated in collecting the samples and clinical information. All authors critically reviewed the manuscript and made key contributions to the analysis and interpretations of the results. All authors contributed to the article and approved the submitted version. 


\section{FUNDING}

This study was financially supported by the Innovative Foundation of Huazhong University of Science and Technology (3004510131) to YH.

\section{ACKNOWLEDGMENTS}

The authors thank members from Dr. Lei Yin's laboratory (College of Life Sciences, Wuhan University) for analyzing the RNA-seq results. We appreciate the personnel from Analytical \&

\section{REFERENCES}

1. Christiansen OB, Nybo Andersen AM, Bosch E, Daya S, Delves PJ, Hviid TV, et al. Evidence-Based Investigations and Treatments of Recurrent Pregnancy Loss. Fertil Steril (2005) 83(4):821-39. doi: 10.1016/j.fertnstert.2004.12.018

2. Practice Committee of the American Society for Reproductive Medicine. Evaluation and Treatment of Recurrent Pregnancy Loss: A Committee Opinion. Fertil Steril (2012) 98(5):1103-11. doi: 10.1016/j.fertnstert.2012.06.048

3. Krieg S, L. W. Immune Function and Recurrent Pregnancy Loss. Semin Reprod Med (2015) 33(04):305-12. doi: 10.1055/s-0035-1554917

4. Medawar P. Some Immunological and Endocrinological Problems Raised by the Evolution of Viviparity. Symp Soc Exp Biol (1952) 7.

5. Mor G, Aldo P, Alvero AB. The Unique Immunological and Microbial Aspects of Pregnancy. Nat Rev Immunol (2017) 17(8):469-82. doi: 10.1038/ nri.2017.64

6. Li D, Zheng L, Zhao D, Xu Y, Wang Y. The Role of Immune Cells in Recurrent Spontaneous Abortion. Reprod Sci (2021) 8:1-13. doi: 10.1007/ s43032-021-00599-y

7. Fichtner AS, Ravens S, Prinz I. Human $\gamma \delta$ TCR Repertoires in Health and Disease. Cells (2020) 9(4):800. doi: 10.3390/cells9040800

8. Born WK, Kemal Aydintug M, O’Brien RL. Diversity of $\gamma \delta$ T-Cell Antigens. Cell Mol Immunol (2013) 10(1):13-20. doi: 10.1038/cmi.2012.45

9. Castro CD, Boughter CT, Broughton AE, Ramesh A, Adams EJ. Diversity in Recognition and Function of Human $\gamma \delta$ T Cells. Immunol Rev (2020) 298 (1):134-52. doi: 10.1111/imr.12930

10. Brandes M, Willimann K, Moser B. Professional Antigen-Presentation Function by Human Gammadelta T Cells. Science (2005) 309(5732):264-8. doi: $10.1126 /$ science.1110267

11. Vantourout P, Hayday A. Six-Of-the-Best: Unique Contributions of $\gamma \delta$ T Cells to Immunology. Nat Rev Immunol (2013) 13(2):88-100. doi: 10.1038/nri3384

12. Heyborne KD, Cranfill RL, Carding SR, Born WK, O’Brien RL. Characterization of Gamma Delta T Lymphocytes at the Maternal-Fetal Interface. J Immunol (Baltimore Md 1950) (1992) 149(9):2872-8.

13. Mincheva-Nilsson L, Hammarström S, Hammarström ML. Human Decidual Leukocytes From Early Pregnancy Contain High Numbers of Gamma Delta+ Cells and Show Selective Down-Regulation of Alloreactivity. I Immunol (Baltimore Md 1950) (1992) 149(6):2203-11.

14. Meeusen EN, Bischof RJ, Lee CS. Comparative T-Cell Responses During Pregnancy in Large Animals and Humans. Am J Reprod Immunol (NY NY 1989) (2001) 46(2):169-79. doi: 10.1111/j.8755-8920.2001.460208.x

15. Mincheva-Nilsson L, Baranov V, Yeung MM, Hammarström S, Hammarström ML. Immunomorphologic Studies of Human DeciduaAssociated Lymphoid Cells in Normal Early Pregnancy. J Immunol (Baltimore Md 1950) (1994) 152(4):2020-32.

16. Psarra K, Kapsimali V, Tarassi K, Dendrinos S, Athanasiadis T, Botsis D, et al. TCRgammadelta $+\mathrm{T}$ Lymphocytes in Unexplained Recurrent Spontaneous Abortions. Am J Reprod Immunol (NY NY 1989) (2001) 45(1):6-11. doi: 10.1111/j.8755-8920.2001.450102.x

17. Talukdar A, Rai R, Aparna Sharma K, Rao DN, Sharma A. Peripheral Gamma Delta T Cells Secrete Inflammatory Cytokines in Women With Idiopathic Recurrent Pregnancy Loss. Cytokine (2018) 102(2):117-22. doi: 10.1016/ j.cyto.2017.07.018
Testing Medical Subcenter, Huazhong University of Science \& Technology for conducting the flow cytometry. In particular, we owe a debt of gratitude to all volunteers and RSA patients for supporting this project.

\section{SUPPLEMENTARY MATERIAL}

The Supplementary Material for this article can be found online at: https://www.frontiersin.org/articles/10.3389/fimmu.2021. 724662/full\#supplementary-material

18. Nagaeva O, Jonsson L, Mincheva-Nilsson L. Dominant IL-10 and TGF-Beta mRNA Expression in gammadeltaT Cells of Human Early Pregnancy Decidua Suggests Immunoregulatory Potential. Am J Reprod Immunol (NY NY 1989) (2002) 48(1):9-17. doi: 10.1034/j.1600-0897.2002.01131.x

19. Fan DX, Duan J, Li MQ, Xu B, Li DJ, Jin LP. The Decidual Gamma-Delta T Cells Up-Regulate the Biological Functions of Trophoblasts via IL-10 Secretion in Early Human Pregnancy. Clin Immunol (Orlando Fla) (2011) 141(3):284-92. doi: 10.1016/j.clim.2011.07.008

20. Mincheva-Nilsson L, Nagaeva O, Sundqvist K-G, Hammarström M-L, Hammarström S, Baranov V. $\gamma \delta$ T Cells of Human Early Pregnancy Decidua: Evidence for Cytotoxic Potency. Int Immunol (2000) 12(5):58596. doi: 10.1093/intimm/12.5.585\%JInternationalImmunology

21. Wu K, Feng J, Xiu Y, Li Z, Lin Z, Zhao H, et al. V $\delta 2$ T Cell Subsets, Defined by PD-1 and TIM-3 Expression, Present Varied Cytokine Responses in Acute Myeloid Leukemia Patients. Int Immunopharmacol (2020) 80:106122. doi: 10.1016/j.intimp.2019.106122

22. Chen X-J, Deng Y-R, Wang Z-C, Wei W-F, Zhou C-F, Zhang Y-M, et al. Hypoxia-Induced ZEB1 Promotes Cervical Cancer Progression via CCL8Dependent Tumour-Associated Macrophage Recruitment. Cell Death Dis (2019) 10(7):508. doi: 10.1038/s41419-019-1748-1

23. Polgar B, Barakonyi A, Xynos I, Szekeres-Bartho J. The Role of Gamma/Delta T Cell Receptor Positive Cells in Pregnancy. Am J Reprod Immunol (NY NY 1989) (1999) 41(4):239-44. doi: 10.1111/j.1600-0897.1999.tb00433.x

24. Szekeres-Bartho J, Barakonyi A, Miko E, Polgar B, Palkovics T. The Role Of $/$ $\delta$ t Cells in the Feto-Maternal Relationship. Semin Immunol (2001) 13(4):22933. doi: $10.1006 /$ smim.2000.0318

25. Szekeres-Bartho J, Barakonyi A, Polgar B, Par G, Faust Z, Palkovics T, et al. The Role of Gamma/Delta $\mathrm{T}$ Cells in Progesterone-Mediated Immunomodulation During Pregnancy: A Review. Int J Mol Sci (1999) 42 (1):44-8. doi: 10.3390/ijms20030687

26. Suzuki T, Hiromatsu K, Ando Y, Okamoto T, Tomoda Y, Yoshikai Y. Regulatory Role of Gamma Delta $\mathrm{T}$ Cells in Uterine Intraepithelial Lymphocytes in Maternal Antifetal Immune Response. J Immunol (Baltimore Md 1950) (1995) 154(9):4476-84.

27. Duan J, Jiang XP, Li MQ, Fan DX, Wang Y, Li DJ, et al. Thymic Stromal Lymphopoietin Suppresses the Apoptosis of Decidual Gamma-Delta T Cells via Regulation of the Signal Transduction and Activation of Transcription 3/ Caspase-3 Signaling Pathway. Am J Reprod Immunol (NY NY 1989) (2013) 70 (6):464-71. doi: 10.1111/aji.12158

28. Terzieva A, Dimitrova V, Djerov L, Dimitrova P, Zapryanova S, Hristova I, et al. Early Pregnancy Human Decidua Is Enriched With Activated, Fully Differentiated and Pro-Inflammatory Gamma/Delta T Cells With Diverse TCR Repertoires. Int J Mol Sci (2019) 20(3):687. doi: 10.3390/ijms20030687

29. Barakonyi A, Polgar B, Szekeres-Bartho J. The Role of Gamma/Delta T-Cell Receptor-Positive Cells in Pregnancy: Part II. Am J Reprod Immunol (NY NY 1989) (1999) 42(2):83-7.

30. Iwasaki M, Tanaka Y, Kobayashi H, Murata-Hirai K, Miyabe H, Sugie T, et al. Expression and Function of PD-1 in Human $\gamma \delta \mathrm{T}$ Cells That Recognize Phosphoantigens. Eur J Immunol (2011) 41(2):345-55. doi: 10.1002/eji.201040959

31. Aktas E, Kucuksezer UC, Bilgic S, Erten G, Deniz G. Relationship Between CD107a Expression and Cytotoxic Activity. Cell Immunol (2009) 254(2):14954. doi: 10.1016/j.cellimm.2008.08.007 
32. Clark DA, Croitoru K. TH1/TH2,3 Imbalance Due to Cytokine-Producing NK, Gammadelta T and NK-Gammadelta T Cells in Murine Pregnancy Decidua in Success or Failure of Pregnancy. Am J Reprod Immunol (N Y NY 1989) (2001) 45(5):257-65. doi: 10.1111/j.8755-8920.2001.450501.x

33. Wen L, Barber DF, Pao W, Wong FS, Owen MJ, Hayday A. Primary Gamma Delta Cell Clones can be Defined Phenotypically and Functionally as Th1/Th2 Cells and Illustrate the Association of CD4 With Th2 Differentiation. J Immunol (Baltimore Md 1950) (1998) 160(4):1965-74.

34. Starr ME. Unique Transcriptome of Age-Associated Visceral Fat-Resident Gamma Delta T Cells. Innov Aging (2019) 3(Suppl 1):S964-S. doi: 10.1093/ geroni/igz038.3496

35. Lahmers KK, Hedges JF, Jutila MA, Deng M, Abrahamsen MS, Brown WC. Comparative Gene Expression by $\mathrm{WC} 1+\gamma \delta$ and $\mathrm{CD} 4+\alpha \beta$ T Lymphocytes, Which Respond to Anaplasma Marginale, Demonstrates Higher Expression of Chemokines and Other Myeloid Cell-Associated Genes by WC1+ $\gamma \delta \mathrm{T}$ Cells. J Leukocyte Biol (2006) 80(4):939-52. doi: 10.1189/jlb.0506353

36. Wu D, Wu P, Wu X, Ye J, Wang Z, Zhao S, et al. Ex Vivo Expanded Human Circulating V $\delta 1 \gamma \delta$ t Cells Exhibit Favorable Therapeutic Potential for Colon Cancer. Oncoimmunology (2015) 4(3):e992749. doi: 10.4161/2162402X. 2014.992749

37. Xu P, Zhang F, Chang M-M, Zhong C, Sun C-H, Zhu H-R, et al. Recruitment of $\gamma \delta \mathrm{T}$ Cells to the Lesion via the CCL2/CCR2 Signaling After Spinal Cord Injury. J Neuroinflamm (2021) 18(1):64. doi: 10.1186/s12974-021-02115-0

38. Lança T, Costa MF, Gonçalves-Sousa N, Rei M, Grosso AR, Penido C, et al. Protective Role of the Inflammatory CCR2/CCL2 Chemokine Pathway Through Recruitment of Type 1 Cytotoxic $\gamma \delta$ T Lymphocytes to Tumor Beds. J Immunol (2013) 190(12):6673. doi: 10.4049/jimmunol.1300434

39. Devaud C, Bilhere E, Loizon S, Pitard V, Behr C, Moreau JF, et al. Antitumor Activity of Gammadelta T Cells Reactive Against Cytomegalovirus-Infected Cells in a Mouse Xenograft Tumor Model. Cancer Res (2009) 69(9):3971-8. doi: 10.1158/0008-5472.Can-08-3037

40. Glatzel A, Wesch D, Schiemann F, Brandt E, Janssen O, Kabelitz D. Patterns of Chemokine Receptor Expression on Peripheral Blood $\gamma \delta$ T Lymphocytes: Strong Expression of CCR5 Is a Selective Feature of $\mathrm{V} \delta 2 / \mathrm{V} \gamma 9 \gamma \delta \mathrm{T}$ Cells. J Immunol (2002) 168(10):4920. doi: 10.4049/jimmunol.168.10.4920

41. Voskakis I, Tsekoura C, Keramitsoglou T, Tsantoulas E, Deligeoroglou E, Creatsas G, et al. Chlamydia Trachomatis Infection and $\mathrm{V} \gamma 9 \mathrm{v} \delta 2 \tau$ Cells in Women With Recurrent Spontaneous Abortions. Am J Reprod Immunol (NY NY 1989) (2016) 76(5):358-63. doi: 10.1111/aji.12554

42. Liang Q, Tong L, Xiang L, Shen S, Pan C, Liu C, et al. Correlations of the Expression of $\gamma \delta$ T Cells and Their Co-Stimulatory Molecules TIGIT, PD-1, ICOS and BTLA With PR and PIBF in the Peripheral Blood and Decidual Tissues of Women With Unexplained Recurrent Spontaneous Abortion. Clin Exp Immunol (2021) 203(1):55-65. doi: 10.1111/cei.13534

43. Cai D, Tang Y, Yao X. Changes of $\gamma \delta t$ Cell Subtypes During Pregnancy and Their Influences in Spontaneous Abortion. J Reprod Immunol (2019) 131:5762. doi: 10.1016/j.jri.2019.01.003

44. Arck PC, Ferrick DA, Steele-Norwood D, Egan PJ, Croitoru K, Carding SR, et al. Murine T Cell Determination of Pregnancy Outcome. Cell Immunol (1999) 196(2):71-9. doi: 10.1006/cimm.1999.1535

45. Wherry EJ, Kurachi M. Molecular and Cellular Insights Into T Cell Exhaustion. Nat Rev Immunol (2015) 15(8):486-99. doi: 10.1038/nri3862

46. Vigano S, Bobisse S, Coukos G, Perreau M, Harari A. Cancer and HIV-1 Infection: Patterns of Chronic Antigen Exposure. Front Immunol (2020) 11:1350. doi: $10.3389 /$ fimmu.2020.01350

47. Farrukh H, El-Sayes N, Mossman K. Mechanisms of PD-L1 Regulation in Malignant and Virus-Infected Cells. Int J Mol Sci (2021) 22(9):4893. doi: 10.3390/ijms22094893

48. Li Z, Zheng B, Qiu X, Wu R, Wu T, Yang S, et al. The Identification and Functional Analysis of CD8+PD-1+CD161+ T Cells in Hepatocellular Carcinoma. NPJ Precis Oncol (2020) 4(1):28. doi: 10.1038/s41698-020-00133-4

49. Morita K, Tsuda S, Kobayashi E, Hamana H, Tsuda K, Shima T, et al. Analysis of TCR Repertoire and PD-1 Expression in Decidual and Peripheral CD8+ T Cells Reveals Distinct Immune Mechanisms in Miscarriage and Preeclampsia. Front Immunol (2020) 11: (1082)11:1082. doi: 10.3389/fimmu.2020.01082

50. Agata $Y$, Kawasaki A, Nishimura H, Ishida $Y$, Tsubat $T$, Yagita H, et al. Expression of the PD-1 Antigen on the Surface of Stimulated Mouse T and B Lymphocytes. Int Immunol (1996) 8(5):765-72. doi: 10.1093/intimm/8.5.765
51. Funderburg NT, Jiang Y, Debanne SM, Labbato D, Juchnowski S, Ferrari B, et al. Rosuvastatin Reduces Vascular Inflammation and T-Cell and Monocyte Activation in HIV-Infected Subjects on Antiretroviral Therapy. J Acquir Immune Defic Syndr (2015) 68(4):396-404. doi: 10.1097/QAI.0000000000000478

52. Sauce D, Almeida JR, Larsen M, Haro L, Autran B, Freeman GJ, et al. PD-1 Expression on Human CD8 T Cells Depends on Both State of Differentiation and Activation Status. AIDS (2007) 21(15):2005-13. doi: 10.1097/QAD.0b0 13 e3282eee 548

53. Li H, Xiang Z, Feng T, Li J, Liu Y, Fan Y, et al. Human V $\gamma 9 v \delta 2-T$ Cells Efficiently Kill Influenza Virus-Infected Lung Alveolar Epithelial Cells. Cell Mol Immunol (2013) 10(2):159-64. doi: 10.1038/cmi.2012.70

54. Chowdhury D, Lieberman J. Death by a Thousand Cuts: Granzyme Pathways of Programmed Cell Death. Annu Rev Immunol (2008) 26(1):389-420. doi: 10.1146/annurev.immunol.26.021607.090404

55. Baran K, Dunstone M, Chia J, Ciccone A, Browne KA, Clarke CJP, et al. The Molecular Basis for Perforin Oligomerization and Transmembrane Pore Assembly. Immunity (2009) 30(5):684-95. doi: 10.1016/j.immuni.2009.03.016

56. Dias C, Gois BM, Lima VS, Guerra-Gomes IC, Araújo JMG, Gomes J, et al. Human CD8 T-Cell Activation in Acute and Chronic Chikungunya Infection. Immunology (2018) 155(4):499-504. doi: 10.1111/imm.12992

57. Ma Y, Gong J, Liu Y, Guo W, Jin B, Wang X, et al. MicroRNA-30c Promotes Natural Killer Cell Cytotoxicity via Up-Regulating the Expression Level of NKG2D. Life Sci (2016) 151:174-81. doi: 10.1016/j.lfs.2016.03.012

58. Chen P-Y, Wu C, Fang J-H, Chen H-C, Feng L-Y, Huang CA, et al. Functional Change of Effector Tumor-Infiltrating CCR5+CD38+HLA-DR+CD8+ T Cells in Glioma Microenvironment. Front Immunol (2019) 10:2395. doi: 10.3389/ fimmu.2019.02395

59. Nörenberg J, Jaksó P, Barakonyi A. Gamma/Delta T Cells in the Course of Healthy Human Pregnancy: Cytotoxic Potential and the Tendency of CD8 Expression Make CD56+ $\gamma \delta$ t Cells a Unique Lymphocyte Subset. Front Immunol (2021) 11:596489. doi: 10.3389/fimmu.2020.596489

60. Gomez-Lopez N, StLouis D, Lehr MA, Sanchez-Rodriguez EN, ArenasHernandez M. Immune Cells in Term and Preterm Labor. Cell Mol Immunol (2014) 11(6):571-81. doi: 10.1038/cmi.2014.46

61. Meggyes M, Lajko A, Palkovics T, Totsimon A, Illes Z, Szereday L, et al. FetoMaternal Immune Regulation by TIM-3/Galectin-9 Pathway and PD-1 Molecule in Mice at Day 14.5 of Pregnancy. Placenta (2015) 36(10):115360. doi: 10.1016/j.placenta.2015.07.124

62. Wegmann TG, Lin H, Guilbert L, Mosmann TR. Bidirectional Cytokine Interactions in the Maternal-Fetal Relationship: Is Successful Pregnancy a TH2 Phenomenon? Immunol Today (1993) 14(7):353-6. doi: 10.1016/01675699(93)90235-D

63. Silva-Santos B, Mensurado S, Coffelt SB. $\gamma \delta$ T Cells: Pleiotropic Immune Effectors With Therapeutic Potential in Cancer. Nat Rev Cancer (2019) 19 (7):392-404. doi: 10.1038/s41568-019-0153-5

64. Paul S, Singh AK, Shilpi, Lal G. Phenotypic and Functional Plasticity of Gamma-Delta $(\gamma \delta)$ T Cells in Inflammation and Tolerance. Int Rev Immunol (2014) 33(6):537-58. doi: 10.3109/08830185.2013.863306

65. McKenzie DR, Comerford I, Silva-Santos B, McColl SR. The Emerging Complexity of $\gamma \delta$ t17 Cells. Front Immunol (2018) 9:796. doi: 10.3389/ fimmu.2018.00796

66. Hu G, Wu P, Cheng P, Zhang Z, Wang Z, Yu X, et al. Tumor-Infiltrating CD39+ $\gamma \delta$ tregs Are Novel Immunosuppressive T Cells in Human Colorectal Cancer. Oncoimmunology (2017) 6(2):e1277305. doi: 10.1080/ 2162402X.2016.1277305

67. Pinget GV, Corpuz TM, Stolp J, Lousberg EL, Diener KR, Robertson SA, et al. The Majority of Murine Gamma Delta T Cells at the Maternal-Fetal Interface in Pregnancy Produce IL-17. Immunol Cell Biol (2016) 94(7):623-30. doi: 10.1038/icb.2016.48

68. Polese B, Gridelet V, Perrier d'Hauterive S, Renard C, Munaut C, Martens H, et al. Accumulation of IL-17+V $\gamma 6+\gamma \delta$ T Cells in Pregnant Mice Is Not Associated With Spontaneous Abortion. Clin Trans Immunol (2018) 7(1): e1008. doi: $10.1002 / \mathrm{cti} 2.1008$

69. Hayakawa S, Karasaki-Suzuki M, Itoh T, Ishii M, Kanaeda T, Nagai N, et al. Effects of Paternal Lymphocyte Immunization on Peripheral Th1/Th2 Balance and TCR V Beta and V Gamma Repertoire Usage of Patients With Recurrent Spontaneous Abortions. Am J Reprod Immunol (NY NY 1989) (2000) 43 (2):107-15. doi: 10.1111/j.8755-8920.2000.430207.x 
70. Iwakura Y, Nakae S, Saijo S, Ishigame H. The Roles of IL-17A in Inflammatory Immune Responses and Host Defense Against Pathogens. Immunol Rev (2008) 226(1):57-79. doi: 10.1111/j.1600-065X.2008.00699.x

71. Krueger JG, Fretzin S, Suárez-Fariñas M, Haslett PA, Phipps KM, Cameron GS, et al. IL-17A Is Essential for Cell Activation and Inflammatory Gene Circuits in Subjects With Psoriasis. J Allergy Clin Immunol (2012) 130(1):14554.e9. doi: 10.1016/j.jaci.2012.04.024

72. Chen K, Kolls JK. Interluekin-17a (IL17A). Gene (2017) 614:8-14. doi: 10.1016/j.gene.2017.01.016

73. Meeusen E, Fox A, Brandon M, Lee CS. Activation of Uterine Intraepithelial Gamma Delta T Cell Receptor-Positive Lymphocytes During Pregnancy. Eur J Immunol (1993) 23(5):1112-7. doi: 10.1002/eji.1830230520

74. Mincheva-Nilsson L, Kling M, Hammarstrom S, Nagaeva O, Sundqvist KG, Hammarstrom ML, et al. Gamma Delta T Cells of Human Early Pregnancy Decidua: Evidence for Local Proliferation, Phenotypic Heterogeneity, and Extrathymic Differentiation. J Immunol (Baltimore Md 1950) (1997) 159 (7):3266-77.

75. Hayakawa S, Saito S, Nemoto N, Chishima F, Akiyama K, Shiraishi H, et al. Expression of Recombinase-Activating Genes (RAG-1 and 2) in Human Decidual Mononuclear Cells. J Immunol (Baltimore Md 1950) (1994) 153 (11):4934-9.

76. Kimura M, Hanawa H, Watanabe H, Ogawa M, Abo T. Synchronous Expansion of Intermediate TCR Cells in the Liver and Uterus During Pregnancy. Cell Immunol (1995) 162(1):16-25. doi: 10.1006/cimm.1995.1046

77. Liu WJ, Gottshall SL, Hansen PJ. Increased Expression of Cell Surface Markers on Endometrial Gamma Delta T-Cell Receptor+ Intraepithelial Lymphocytes Induced by the Local Presence of the Sheep Conceptus. Am J
Reprod Immunol (NY NY 1989) (1997) 37(2):199-205. doi: 10.1111/j.16000897.1997.tb00214.x

78. Heyborne K, Fu YX, Nelson A, Farr A, O’Brien R, Born W. Recognition of Trophoblasts by Gamma Delta T Cells. J Immunol (Baltimore Md 1950) (1994) 153(7):2918-26.

79. Haller H, Radillo O, Rukavina D, Tedesco F, Candussi G, Petrović O, et al. An Immunohistochemical Study of Leucocytes in Human Endometrium, First and Third Trimester Basal Decidua. J Reprod Immunol (1993) 23(1):41-9. doi: 10.1016/0165-0378(93)90025-d

Conflict of Interest: The authors declare that the research was conducted in the absence of any commercial or financial relationships that could be construed as a potential conflict of interest.

Publisher's Note: All claims expressed in this article are solely those of the authors and do not necessarily represent those of their affiliated organizations, or those of the publisher, the editors and the reviewers. Any product that may be evaluated in this article, or claim that may be made by its manufacturer, is not guaranteed or endorsed by the publisher.

Copyright (C) 2021 Yu, Zhang, Xiong, Liu, Zha, Kang, Zhi, Wang, Wang, Zeng and Huang. This is an open-access article distributed under the terms of the Creative Commons Attribution License (CC BY). The use, distribution or reproduction in other forums is permitted, provided the original author(s) and the copyright owner(s) are credited and that the original publication in this journal is cited, in accordance with accepted academic practice. No use, distribution or reproduction is permitted which does not comply with these terms. 